\title{
Stability of Risk Preference Measures: Results From a Field Experiment on French Farmers*
}

\author{
Arnaud Reynaud $^{\dagger}$ and Stéphane Couture ${ }^{\ddagger}$
}

May 3, 2010

\begin{abstract}
We compare three different elicitation methods for measuring risk attitudes of French farmers in a field experiment setting. We consider two experiments based on the lottery choices initially proposed by Holt and Laury (2002) and by Eckel and Grossman (2002,2008), a risk-taking psychological questionnaire and a self-reporting of perceived risk attitudes for different domains. The main empirical results from this within-subject study are the following. First, within the class of lottery choices, risk preference measures are affected by the type of mechanism used. In particular, farmers appear to be more risk averse using the Eckel and Grossman lottery than using the Holt and Laury one. However attitudes towards risk are significantly correlated across lotteries which means that the ranking of risk preferences seems to be preserved. Second, risk preferences appear to be context-dependent. French farmers are highly risk averse for decisions belonging to financial and ethical domains. They report a higher willingness to take risk for professional decisions. Lastly, using the psychological questionnaire, we find that the risk attitude elicited through lottery choices often correlates with risk attitude toward investments. These findings contribute to the literature which addresses the stability of risk preferences across elicitation methods.
\end{abstract}

Keywords: risk preferences, psychological economics, field experiment, experimental economics

\section{JEL Codes: C91; D8; J16; Q12}

${ }^{*}$ The authors thank Jérôme Duruy for having conducted the field survey. We are grateful to Olivier Armantier, Giuseppe Attanasi, Cécile Aubert, Astrid Hopfensitz, Christoph Heinzel and to all participants of the 2010 IMEBE conference at Bilbao for their relevant comments on a preliminary draft. This work has been completed within the UMT-EAU which associates the French Agronomic Research Institute (INRA) and two farmer advisor structures (Arvalis Institut du Végétal and CETIOM). Financial support from the research program "Eaux et Territoires" and the Midi-Pyrénées region for the research projet EAUSAGE-quant is recognized.

${ }^{\dagger}$ Toulouse School of Economics (LERNA-INRA) Université de Toulouse 1 Capitole, Manufacture des Tabacs Bât.F, 21 allée de Brienne, 31042 Toulouse. France. E-mail: areynaud@toulouse.inra.fr, fax: (33)-5-61-12-85-20, tel: (33)-5-61-12-85-12. Corresponding author.

${ }^{\ddagger}$ INRA, UR 875 BIA, 31326 Castanet-Tolosan, France. E-mail: scouture@toulouse.inra.fr, tel: (33)-5-61-28-57- 40. 


\section{Introduction}

Risk and uncertainty play a significant role in almost every important economic decision. Since people differ in the way they take decisions involving risk and uncertainty and since these differences are often described as differences in risk attitude, understanding individual risk preferences is a prerequisite to understand economic behavior. As a result, numerous researchers have studied individual risk attitudes in a variety of fields and settings, Blais and Weber (2006). Surprisingly the different methods used for measuring risk attitudes have been shown to result in different classifications of individuals. More importantly, even when using the same assessment method, individuals have not shown themselves to be consistently risk seeking or risk averse, Schoemaker (1990). Our main objective is to contribute to this literature by comparing the risk attitude elicited by various methodologies on the same sample of subjects.

Controlled laboratory experiments have been used for a long time to study risk attitudes. Numerous researchers have attempted to elicit certainty equivalents for lotteries through theoretically truthfully revealing mechanisms such as the Becker, Degroot and Marshak (BDM) procedure. An alternative approach that has been used extensively to measure risk attitudes is through observing bids in private value auctions. Holt and Laury (2002) have developed a series of binary comparisons in which the prizes are the same for each comparison but the probability of receiving the higher payoff varies across comparisons. Eckel and Grossman $(2002,2008)$ have constructed a similar method but hold the probabilities fixed and vary the payoffs. A troubling result from this experimental literature is that the degree of risk aversion of an individual varies across elicitation techniques over similar sized stakes. For instance, Isaac and James (2000) compare individual risk attitudes elicited using a first-price auction and the BDM pricing procedure. They find that subjects appear to be risk averse in the first-price auction but often risk-neutral in BDM. They also report that the ranking across subjects of risk parameters is not preserved across the two elicitation methods. We propose to build on this recent literature by eliciting risk preferences using two different lottery tasks, namely the Eckel and Grossman mechanism (henceforth EG) and the Holt and Laury mechanism (henceforth HL). These tasks have been extensively used and validated in various contexts.

A recent work by Deck et al. (2008) has suggested that the instability of risk preferences across experimental tasks could be related to the fact that risk attitudes may vary depending on the context. The literature in psychology has suggested that it is appropriate to consider risk attitudes as a personality trait, Weber, Blais, and Betz (2002). While traits were initially defined as stable (i.e., situation invariant), empirical observations suggest that risk-taking is in fact highly 
domain specific. ${ }^{1}$ With this in mind, psychologists have developed some tests to assess individual willingness to engage in risky decision-making across a variety of domains. The Domain-Specific Risk-Taking (DOSPERT) test provided by Weber, Blais, and Betz (2002) is an example of such a psychologist test since it allows to identify risk preferences for seven different domains (e.g., social, recreational, health, safety, gambling, ethical, and investments). We propose to use a psychometric questionnaire to assess subject risk preferences for various domains and we check if the HL and the EG tasks provide a measure of risk preferences for the same domains or, on contrary, for different domains. If the HL and the EG tasks provide some measures of risk preferences for distinct domains, one may understand why the level of risk aversion elicited through these two methods may vary.

Compared to the existing literature on risk preference elicitation, we use a field experiment approach and we consider a sample of French farmers. Although most of the literature on risk preference elicitation relies on laboratory experiments, Andersen et al. (2010) have recently stressed that field and laboratory experiments are in fact complementary tools. Hence, field experiments allow to extrapolate findings from the laboratory to a population of interest. If some works have been conducted on sub-samples of the population presenting specific characteristics ${ }^{2}$, only a few studies have focused on risk preferences of farmers, especially in the context of developed countries. $^{3}$ There are several reasons why eliciting risk preferences on a sample of farmers is worth being undertaken. First, since farmers are used in their professional life to take decisions under uncertainty (cropping choice is subject to production and market risks), instability in preferences due to differences in cognitive difficulty across elicitation methods should be limited, Anderson and Mellor (2008). Second, there is currently no consensus in the agricultural economics literature on the level of farmer's risk aversion, see Reynaud et al. (2009). Lastly, from a policy-oriented point of view, a valid measure of risk attitudes is a critical input for properly designing agricultural price or income support instruments.

Our results demonstrate that, within the class of lottery choices, risk preference measures are affected by the type of mechanism used. In particular, farmers appear to be more risk averse using the EG lottery than using the HL one. Since attitudes towards risk are significantly correlated across lotteries, ranking of risk preferences seems however to be preserved across lottery tasks.

\footnotetext{
${ }^{1}$ MacCrimmon and Wehrung (1990) have showed that executive managers have different risk attitudes when making decisions involving personal versus company money or when evaluating financial versus recreational risks.

${ }^{2}$ Kihlstrom and Laffont (1979) have proposed a framework in which entrepreneurs are less risk averse than the rest of the population. This idea has resulted in an important empirical literature. For instance, Sarasvathy, Simon, and Lave (1998) find significant differences in risk preferences between entrepreneurs and bankers.

${ }^{3}$ Elicitation of farmer risk preferences in the context of developing countries is much more common. See for instance the seminal works Binswanger (1980) and Quizon, Binswanger, and Machina (1984) who considered an ordered lottery selection design to elicit risk preferences of Indian farmers. Tanaka, Camerer, and Nguyen (2009) provide a more recent application of multiple price list methods to elicit risk preferences on a sample of Vietnamese farmers.
} 
Second, risk preferences appear to be context-dependent. French farmers are highly risk averse for decisions belonging to financial and ethical domains. They report a higher willingness to take risk for professional decisions. Lastly, using the psychological questionnaire, we find that the risk attitude elicited through lottery choices often correlates with risk attitude toward investments.

The remainer of the paper is organized as follows. In Section 2, we survey studies that have employed a within-subjects design to assess the impact of using various elicitation methods to compare risk preferences. Then, we describe our experimental design including the elicitation techniques and the survey instruments. The results related to risk preferences are presented in Section 4. Lastly, Section 5 is devoted the stability of risk attitude across the various elicitation techniques.

\section{Relevant Literature}

Several studies have reported that risk preferences may not appear stable across the design of laboratory experiments. ${ }^{4}$ In this section, we focus exclusively on studies that have employed a within-subjects design to compare various elicitation methods concerning risk preferences.

\subsection{Stability across experimental tasks}

Controlled laboratory experiments (lotteries for instance) have been used to study risk attitudes for a long time. ${ }^{5}$ A troubling result from this experimental literature is that the degree of risk aversion of an individual varies across elicitation techniques over similar sized stakes.

Isaac and James (2000) compare individual risk attitudes elicited through a first-price auction and the Becker, Degroot, and Marschack (BDM) pricing procedure. They find that subjects appear to be risk averse in the first-price auction but often risk-neutral in BDM. They also report that across subjects the ranking of risk parameters is not preserved across the two elicitation methods. Berg, Dickhaut, and McCabe (2005) consider three different mechanisms for eliciting individual preferences namely the BDM pricing procedure, an English clock auction, and a first-price auction. They find dramatic differences in elicited preferences and they report that subjects act as risk-loving in the English clock auctions and as risk-averse in the first-price auctions. Dave et al. (2007) elicit

\footnotetext{
${ }^{4}$ Andersen et al. (2008) have for instance addressed the issue of time stability whereas Kachelmeier and Shehata (1992) or Holt and Laury (2002) have considered the relationship between elicited risk preferences and level or the nature (real versus hypothetical) of financial incentives.

${ }^{5}$ Numerous researchers have attempted to elicit certainty equivalents for lotteries through theoretically truthfully revealing mechanisms such as the Becker, Degroot and Marshak procedure. An alternative approach to measuring risk attitudes is through observing bids in first price private value auctions as mentioned above. Holt and Laury (2002) have developed a series of binary comparisons in which the prizes are the same for each comparison but the probability of receiving the higher payoff varies across comparisons. Eckel and Grossman (2002) have constructed a similar method but hold the probabilities fixed and vary the payoffs. Recently, Bruner (2009) also compares changes in probability to changes in rewards. He concludes to the presence of substantial inconsistency in choices.
} 
individual risk preferences using two lottery tasks: the HL and the EG mechanisms. They find that the two tasks yield to different risk preference estimates: subjects exhibit a greater risk aversion in the HL task than in the EG one. They suggest that this difference may be attributed to the fact that the HL task is cognitively more difficult than the EG one. ${ }^{6}$ Hence, Dave et al. (2007) report that excluding subjects with lower math ability leads to similar estimates of predictive accuracy across the two experimental elicitation methods.

The question addressed by Ivanova-Stenzel and Salmon (2004) is also related to our analysis. They have developed an experimental design aimed at eliciting and measuring subject's preferences for two auction institutions, i.e. an ascending and a sealed-bid first-price auction. ${ }^{7}$ Their main finding is that while subjects exhibit strong preferences for the ascending auction (at equal entry prices), they are not willing to pay up to the expected profit difference between the two auctions to participate in an ascending auction. Ivanova-Stenzel and Salmon (2004) show that one possible answer to the puzzle is that bidders are risk averse in their bidding behavior and also risk averse to the same degree in their auction choice behavior. Ivanova-Stenzel and Salmon (2008) introduce loss aversion and aversion to the dynamic bidding process (ascending auction) as alternative explanations. These two types of risk aversion cannot explain auction choice behaviors, leaving risk aversion as the only remaining hypothesis.

\subsection{Experimental tasks versus hypothetical gambles}

Some works have compared the risk preferences elicited through an experimental task to the preferences derived from a survey instrument which measures the degree of risk aversion directly albeit based upon hypothetical responses.

Deck et al. (2008) consider two experimental tasks (the HL task and a variation of the game show "Deal or No Deal") and two hypothetical gambles. In the inheritance gamble, subjects are asked how much of $\$ 100,000$ in lottery winnings they would invest in an asset that would either double or halve in value over the next two years. In the job gamble, respondents complete questions regarding a hypothetical scenario in which they could accept a new job that would either double their income or cut it by some fraction with equal probability. First, they find that the risk preference obtained with the HL and the Deal or No Deal tasks are not consistent. ${ }^{8}$ Second, with one exception, none

\footnotetext{
${ }^{6}$ The HL task involves ten decisions between gambles and allows categorization of decision makers into 10 risk categories, while the EG task is simpler, involving a single choice among 6 gambles, but only allows categorization of decision makers into 5 risk categories.

${ }^{7}$ Ivanova-Stenzel and Salmon (2004) indicate that bidders may have preferences between these two auction mechanisms due to the strategic differences between them.

${ }^{8}$ However, since the size of the stakes for these tasks are not the same (the average payment in the Deal or No Deal task is approximately six times that of the average payment in the HL task), it is difficult to conclude that there is a task impact on the level of risk preferences.
} 
of the pairwise correlation coefficients between the experiment and survey-based risk preference measures are statistically significant. Anderson and Mellor (2008) compare the risk preferences elicited through the HL task with the same hypothetical gamble (inheritance and job gambles). They find that risk preferences are not stable across elicitation methods. Whereas risk preference estimates from the HL experiment are not associated with subject risk preference classifications from job-based gambles, they report a significant relationship with the inheritance-based gambles. Anderson and Mellor (2008) suggest that individual characteristics such as cognitive comprehension or effort might help understand this discrepancy.

\subsection{Experimental tasks versus psychological measures}

In the psychological literature, risk attitude is viewed has a latent construct (i.e. a not directly observable variable) that is measured by a set of observable variables (i.e. indicators that can be answers from questions).

Deck et al. (2008) use the Weber et al. (2002) psychological risk attitude scale to risk preferences across different situations (social, recreational, health and safety, gambling, ethical, and investment). They conclude that risk attitudes vary within subjects across elicitation methods (experimental tasks versus psychological risk attitude measures). They show that risk attitude towards investment decisions as measured by Weber et al. (2002) influences behavior in the HL task but not in Deal or No Deal. On the contrary, attitudes towards gambling impact behavior in the Deal or No Deal task, but not in the HL task. Deck et al. (2008) propose an explanation derived from the psychological literature. The literature is psychology has suggested that risk attitudes may vary according to the context, Weber et al. (2002). The HL task may be viewed by subjects as an investment task whereas the Deal or No Deal could be associated to gambling. The fact that risk attitude towards investment and gambling may be not the same may explain the discrepancy across elicitation methods reported in Deck et al. (2008).

In Eckel and Grossman (2002,2008), subjects complete a simple 50/50 gamble task and a psychological survey allowing to measure risk attitudes in four different domains. ${ }^{9}$ None of the four measures of risk attitude allows to significantly explain the lottery choice. Eckel and Grossman (2002) conclude that "psychological survey data are not a good predictor of behavior in an incentivized environment where subjects must choose an actual gamble". Another explanation could be that the four domains considered in the psychological survey do not cover the risk domain which is

\footnotetext{
${ }^{9}$ The survey measures different aspects of sensation seeking: the disinhibition (nonconformity with standards of acceptable social behavior), the boredom susceptibility (aversion to routine), a thrill and adventure seeking factor (preference for the thrills inherent in risky activities) and experience seeking (preference for mentally arousing activities and a nonconforming lifestyle).
} 
pertinent for using the EG lottery task choice.

Lastly, Dohmen et al. (2009) compare risk preferences elicited through a lottery choice to self-reported measures of risk aversion in general and in five specific domains (car driving, financial matters, sports and leisure, health matters, and career). ${ }^{10}$ They conclude that the general risk attitude question predicts actual behavior in the lottery quite well. They also show that although self-reported risk attitudes are not perfectly correlated across contexts, the pairwise correlations are large and all highly significant. They attribute this result to the existence of a stable underlying risk trait.

\subsection{Summary}

Most of the recent studies that have used various elicitation methods for assessing risk preferences conclude that risk attitude estimates across methods are greatly unstable. Different explanations have been proposed. For some authors, the reason of this instability should be attributed to differences in cognitive difficulty across elicitation methods, Anderson and Mellor (2008) or Dave et al. (2007). The results obtained by Deck et al. (2008) suggest however that each experimental task may in fact measure risk preferences corresponding to a specific domain.

\section{Experimental Design}

Given the ubiquitous nature of decision making under uncertainty in society, it is no wonder that numerous researchers have studied risk attitudes in a variety of settings. To assess risk preferences, we consider the three following methods:

- Stated preference approach based on financial lotteries;

- Risk-taking psychological questionnaire;

- Self evaluation of risk attitude.

We present in this section the way we implement the three risk preference elicitation methods. We first describe the sampling design. Appendix A presents the different tasks we have used and Appendix B, the full experimental protocol.

\footnotetext{
${ }^{10}$ Subject were asked to evaluate the question "How do you see yourself: are you generally a person who is fully prepared to take risks or do you try to avoid taking risks?" on a 10 point scale going from "not at all willing to take risks" to "very willing to take risks". Subjects were also asked to evaluate the question for the five specific domains mentioned above.
} 


\subsection{Sampling}

Previous works have shown that, in terms of risk preferences, there is an important degree of heterogeneity in the population, Dave et al. (2007). Hence, an accurate measure of risk preferences should take into account this heterogeneity. However, in practice this is not a easy task since it is usually difficult to control for all potential sources of heterogeneity that may have an impact on risk preferences (age, eduction, sex, revenues, etc.). Our strategy has been to consider a population sub-sample in which we expect a lower heterogeneity across subjects and a higher stability of risk preferences across tasks. Instead of using a sample of students, we have considered a sample of French farmers who may be more homogeneous in terms of preferences than the rest of the population. A strong motivation for eliciting risk preferences on a sample of farmers is that they are used in their professional life to taking decisions under uncertainty (climate, production or market uncertainty). We believe that they may be more easily able to compare lotteries in terms of expected utility than the rest of the population. As a result the instability in preferences due to differences in cognitive difficulty across elicitation methods might be limited. Another motivation is that there is currently no consensus in the agricultural economics literature on the level of farmer's risk aversion especially in the context of developed countries (Reynaud et al. (2009)). We wish to contribute to this literature by providing some experimental measures of French farmer's risk aversion. Lastly, from a policy-oriented point of view, a valid measure of risk attitudes is a critical input for properly designing agricultural price or income support instruments. This is especially important since the Common Agricultural Policy reform adopted in June 2003 has implemented a new system for farm income support based on decoupling. Using a sample of Finnish farmers, Koundouri et al. (2009) show for instance that there is a significant relationship between farmers degree of risk aversion and the level of EU subsidy decoupling.

Given the difficulties to organize a lab session with farmers, we decided to use a field experiment approach. ${ }^{11}$ First we selected three different regions in France (Midi-Pyrénées, Poitou-Charentes, Centre) and asked local extension services to provide a listing of farmers located in each area. In order to get a quite homogeneous sample, we restricted the selection to cash crop producers using irrigation. We then randomly selected 10 farmers in each region. None of them refused to take the survey so our sample does not suffer a priori from a selectivity bias.

Given the substantial cost of using a survey firm, and the desire to have more control over all aspect of the field experiment, we decided to undertake the experiments by ourselves. The survey was realized through face-to-face interviews from May to June 2009. The experimental

\footnotetext{
${ }^{11}$ In fact, our experimental framework corresponds to an artefactual field experiment according to the Harrison and List (2004) terminology.
} 
design was the last part of a 3-hour survey aiming at understanding farmer's land use and crop choices. For each subject, the experimental part which lasted around half an hour, was divided into four sub-parts: two experimental lotteries, one personality test and a self-assessment questionnaire of subjects risk attitude. A comprehensive introduction of the methods and goals, and scoreless questions were necessary prior to the four tests to insure a good comprehension. In order to ensure incentive compatibility, subjects are usually informed that after the experiment a random device would determine how much they would be paid according to their decisions. Since, we have not been allowed to pay the subjects, we had to rely on another mechanism. In order to ensure a minimal level of incentives, farmers where explained that after the experiment they would receive a personal risk assessment of their behavior that can be useful to them in their professional of personal life. This personal risk assessment may be viewed as a non-monetary fixed payment. Since the experiment is based on a voluntary participation of all subjects, we believe that farmers interest is high enough to insure that their answers reflect effectively their real preferences. Moreover, Holt and Laury (2002) or Harrison (2006) have found that there are no significant differences in terms of observed decisions between lottery choices using hypothetical or real payoffs.

\subsection{Experimental design for stated preference measures}

In the expected utility framework, differences in risk attitude are modeled by utility functions that differ in shape, with different degrees of concavity to explain risk aversion. Controlled laboratory experiments can then be used to study risk attitudes within this context. We consider two different tasks that have been extensively used in the experimental literature for eliciting risk preference. The first one is derived from Holt and Laury (2002) who have developed a series of binary comparisons in which payoffs are the same for each comparison but probability of receiving the higher payoff varies across comparisons. We also adapt the task initially proposed in Eckel and Grossman (2002).

\subsubsection{Adaptation of the Holt and Laury (HL) experiment}

The first lottery task is an adaptation of the well known "multiple price list" proposed by Holt and Laury (2002) for the elicitation of risk attitudes. In the HL task, subjects are shown different binary lotteries and must select either option A (the "safe" lottery) or option B for each one (the "risky" lottery). The payoffs for option A are fixed at $\$ 2.00$ and $\$ 1.60$ while the payoffs for option B are fixed at $\$ 3.85$ and $\$ 0.10$. As noted by Holt and Laury, the payoffs for the safe lottery (Option A) are less variable than those for the risky lottery (Option B). In each successive row, the likelihood of receiving the larger payoff increases. In the final row there is no uncertainty and monotonicity 
alone is sufficient to lead a person to select option B. By assuming constant relative risk aversion, the subject risk aversion is then directly related to the line at which he switches from preferring option A to preferring option B going down the table.

Table 1: Adaptation of Holt and Laury task

\begin{tabular}{cccccccc}
\hline & & \multicolumn{2}{c}{ Option A } & \multicolumn{2}{c}{ Option B } & Implied Range & CRRA \\
Prob. 1 & Prob. 2 & Payoff 1 & Payoff 2 & Payoff 1 & Payoff 2 & of CRRA & code $^{a}$ \\
\hline $1 / 10$ & $9 / 10$ & 20.0 & 16.0 & 38.5 & 1.0 & $\mathrm{r} \leq-0.95$ & RL3 \\
$2 / 10$ & $8 / 10$ & 20.0 & 16.0 & 38.5 & 1.0 & $\mathrm{r} \leq-0.95$ & RL3 \\
$3 / 10$ & $7 / 10$ & 20.0 & 16.0 & 38.5 & 1.0 & $-0.95<\mathrm{r} \leq-0.49$ & $\mathrm{RL} 2$ \\
$4 / 10$ & $6 / 10$ & 20.0 & 16.0 & 38.5 & 1.0 & $-0.49<\mathrm{r} \leq-0.15$ & $\mathrm{RL} 1$ \\
$5 / 10$ & $5 / 10$ & 20.0 & 16.0 & 38.5 & 1.0 & $-0.15<\mathrm{r} \leq 0.15$ & $\mathrm{RN}$ \\
$6 / 10$ & $4 / 10$ & 20.0 & 16.0 & 38.5 & 1.0 & $0.15<\mathrm{r} \leq 0.41$ & $\mathrm{RA} 1$ \\
$7 / 10$ & $3 / 10$ & 20.0 & 16.0 & 38.5 & 1.0 & $0.41<\mathrm{r} \leq 0.68$ & $\mathrm{RA2}$ \\
$8 / 10$ & $2 / 10$ & 20.0 & 16.0 & 38.5 & 1.0 & $0.68<\mathrm{r} \leq 0.97$ & RA3 \\
$9 / 10$ & $1 / 10$ & 20.0 & 16.0 & 38.5 & 1.0 & $0.97<\mathrm{r} \leq 1.37$ & RA4 \\
$10 / 10$ & $0 / 10$ & 20.0 & 16.0 & 38.5 & 1.0 & $1.37 \leq \mathrm{r}$ & RA5 \\
\hline
\end{tabular}

All payoffs measured in euros

${ }^{a}$ : RL, RN and RA respectively for risk lover, neutral and averse.

We have chosen to use the framework provided by Holt and Laury (2002) except that the payoffs have been converted in euros and modified in order to represent a larger amount of money. In fact, all payoffs for options $\mathrm{A}$ and $\mathrm{B}$ have been converted in euros and multiplied by 10 compared to the original task. As a result, the implied range for the CRRA parameter are not modified. The payoffs we have considered are presented in Table 1. Column 7 in Table 1 provides the implied CRRA consistent with a subject first selecting option B on that decision. For example, a risk neutral person would select option A in the first four rows of Table 1 and option B in the last 6 rows. The last column gives the CRRA code that will be used in the remaining of the paper. Risk lover preferences correspond to a CRRA parameter smaller than -0.15 whereas a subject will be risk averse if the CRRA parameter is greater than 0.15. All instructions used are presented in Appendix B.

Holt and Laury (2002) have examined stake size effects by scaling these payoffs by factors up to 90 times the original values. Their general result is that the elicited risk aversion increases with the size of the stakes. We also test the presence of stake size effects. As a result, subjects have been asked to complete the same lottery task except that all payoffs have been multiplied by a factor 20 . This second task will be called the HL lottery with high payoffs, the first one being called the HL lottery with low payoffs. 


\subsubsection{Adaptation of the Eckel and Grossman (EG) experiment}

The second lottery task played by subjects is an adaptation of recent task proposed by Eckel and Grossman $(2002,2008)$ for the elicitation of individual risk attitudes. Eckel and Grossman $(2002,2008)$ have proposed a simple experiment allowing to measure risk attitude. Their experiment consists in asking subjects to choose from among six possible gambles the one they prefer. All the gambles involve a 50/50 chance of a low or high payoff. ${ }^{12}$ The range of gambles includes a safe alternative involving a sure payoff with zero variance. The gambles increase in both expected return and risk (standard deviation of the expected payoff) moving from Gamble 1 to 5. More risk-averse subjects would choose lower-risk, lower-return gambles.

Table 2: Adaptation of the Eckel and Grossman lottery

\begin{tabular}{ccccc}
\hline $\begin{array}{c}\text { Choice } \\
\text { 50/50 gamble }\end{array}$ & Payoff 1 & Payoff 2 & $\begin{array}{c}\text { Implied range } \\
\text { of CRRA }\end{array}$ & $\begin{array}{c}\text { CRRA } \\
\text { code }\end{array}$ \\
\hline Gamble 1 & 40 & 40 & $\mathrm{r}>1.37$ & RA5 \\
Gamble 2 & 32 & 51 & $0.97<\mathrm{r} \leq 1.37$ & RA4 \\
Gamble 3 & 24 & 64 & $0.68<\mathrm{r} \leq 0.97$ & RA3 \\
Gamble 4 & 16 & 78 & $0.41<\mathrm{r} \leq 0.68$ & RA2 \\
Gamble 5 & 12 & 86 & $0.15<\mathrm{r} \leq 0.41$ & RA1 \\
Gamble 6 & 8 & 91.5 & $-0.15<\mathrm{r} \leq 0.15$ & RN \\
Gamble 7 & 6 & 92.9 & $-0.49<\mathrm{r} \leq-0.15$ & RL1 \\
Gamble 8 & 4 & 93.4 & $-0.95<\mathrm{r} \leq-0.49$ & RL2 \\
Gamble 9 & 1 & 93.5 & $\mathrm{r} \leq-0.95$ & RL3 \\
\hline
\end{tabular}

All payoffs measured in euros

For making possible the comparison with the adapted HL lotteries, we have modified both the payoffs proposed originally Eckel and Grossman (2002,2008) and the number of gambles the subjects had to choose among. The payoffs have been chosen first to get the implied ranges of CRRA identical to the adapted HL lotteries and second, to have expected payoffs similar to the adapted HL lotteries. Table 2 presents the adapted Eckel and Grosman lottery that will be compared to the HL one with low payoffs. Table 2 also includes CRRA parameters implied by each possible choice under the assumption of constant relative risk aversion (CRRA). In what follows, this task will be referred as the EG task with low payoffs. To examined a payoff size effect, subjects have been asked to complete the same task but with all payoffs multiplied by a factor 20 . This second task will be called the EG task with high payoffs. All instructions used for these two tasks are presented in Appendix B.

\footnotetext{
${ }^{12}$ This type of lottery is designed to keep the task as simple as possible. Hence, expected payoffs are easy to calculate since they are linear in risk, measured as the standard deviation of payoffs.
} 


\subsection{Risk-taking psychological questionnaire}

Psychologists have developed tests to assess individual willingness to engage in risky decision-making across a variety of domains. The Domain-Specific Risk-Taking (DOSPERT) test provided by Weber et al. (2002) is an example of such a psychological test. It allows to identify risk preferences for seven different domains (e.g., social, recreational, health, safety, gambling, ethical, and investments). It has been described as one of the most useful measures of risk propensity across a number of everyday situations. We have used the simplified version of this questionnaire proposed by Blais and Weber (2006). The survey is made of 30 statements for which a subject must indicate the likelihood that he/she would engage in the described activity or behavior if he/she were to find himsel/herself in that situation. Initially, the DOSPERT scale provides a rating in seven classes from "Extremely Unlikely" to "Extremely Likely". We have added two additional classes to be consistent with the HL and the EG tasks. The DOSPERT scale allows to compute for each individual some scores measuring his/her risk attitude for five domains: health and safety (e.g., seatbelt usage, smoking), social (e.g., confronting one's coworkers or family members), ethical decisions (e.g., cheating on an exam, terminating a comatose family member's life support), financial, recreational. The simplified version of the DOSPERT test we have used is presented in Appendices A and B. Notice that psychometric measures of risk attitude have been extensively used in the economic literature on risk preferences. For instance, Hopfensitz et al. (2008) use a trait measure of sensation seeking, a risk-propensity scale for various life domains and a general risk attitude question to study willingness to take risks, with a special focus on the role of affect.

\subsection{Self evaluation of risk preferences}

Another possible way of measuring individual risk preferences is to rely on the subject to give an assessment of his willingness to take risks. Due to its simplicity this approach is potentially attractive for eliciting a reliable all-around measure of risk attitudes across contexts. A serious concern with the use of this approach is that responses may not be incentive compatible, Dave et al. (2007). As a result, economists are often skeptical that self-reported personal attitudes and traits are behaviorally meaningful since various factors, including self-serving biases, inattention, and strategic motives could cause respondents to distort their reported risk attitudes. This approach has been recently used by Dohmen et al. (2009) on a large sample representative of the resident adult population of Germany. Interestingly, Dohmen et al. (2009) find that responses to the general risk question are a reliable predictor of actual risky behavior. Their findings demonstrate that a simple, qualitative survey measure can generate a meaningful measure of risk attitudes, which maps 
into actual choices in lotteries with real monetary consequences. ${ }^{13}$

As a result, one part of the questionnaire has consisted in asking subjects to give an assessment of their willingness to take risks in various contexts. The first question on attitude towards risk "in general" asked respondents to rank their behavior on a 9 point scale going from not at all risky to more than extremely risky. The next three questions use the same scale and similar wording but refer to risk attitude in specific contexts (professional activity, financial matters, health). The questions used are presented in Appendix B.

\section{Elicitation of risk preferences}

In this section, we present the individual risk measures separately and we compare them with previously reported measures of risk preferences.

\subsection{Elicitation of risk attitude based on lottery choices}

In Table 3, we report the distribution of farmers across risk classes using the HL and then EG adapted experiments.

Table 3: Proportion of subjects by risk class using lottery tasks

\begin{tabular}{|c|c|c|c|c|c|c|c|c|c|}
\hline $\begin{array}{l}\text { CRRA class } \\
\text { CRRA range }\end{array}$ & $\begin{array}{l}\text { RA5 } \\
>1.37\end{array}$ & $\begin{array}{c}\text { RA4 } \\
0.97 ; 1.37\end{array}$ & $\begin{array}{c}\text { RA3 } \\
0.68 ; 0.97\end{array}$ & $\begin{array}{l}\text { RA2 } \\
0.41 ; 0.68\end{array}$ & $\begin{array}{c}\text { RA1 } \\
0.15 ; 0.41\end{array}$ & $\begin{array}{c}\mathrm{RN} \\
-0.15 ; 0.15\end{array}$ & $\begin{array}{c}\text { RL1 } \\
-0.49 ;-0.15\end{array}$ & $\begin{array}{c}\text { RL2 } \\
-0.95 ;-0.49\end{array}$ & $\begin{array}{l}\text { RL3 } \\
<-0.95\end{array}$ \\
\hline \multicolumn{10}{|c|}{ Adapted Holt and Laury experiment } \\
\hline -low payoffs & 0.04 & 0.11 & 0.07 & 0.18 & 0.14 & 0.21 & 0.04 & 0.07 & 0.14 \\
\hline -high payoffs & 0.07 & 0.11 & 0.14 & 0.18 & 0.11 & 0.21 & 0.04 & 0.07 & 0.07 \\
\hline \multicolumn{10}{|c|}{ Adapted Eckel and Grossman experiment } \\
\hline -low payoffs & 0.29 & 0.07 & 0.21 & 0.07 & 0.11 & 0.04 & 0.00 & 0.00 & 0.21 \\
\hline -high payoffs & 0.29 & 0.36 & 0.07 & 0.07 & 0.11 & 0.04 & 0.00 & 0.00 & 0.07 \\
\hline
\end{tabular}

In the HL experiment, $54 \%$ of subjects appear to be risk-averse for low payoffs. $21 \%$ of the subjects are risk-neutral and $25 \%$ are risk-lover. In case of a high payoff, the subjects appear slightly more risk averse (60\% of the subjects are risk-averse). However, based on a Kornbrot test, the distribution of subjects across risk classes with low and high payoffs are not statistically different. ${ }^{14}$ This result means that risk aversion measured using the HL experiment is not modified

\footnotetext{
${ }^{13}$ Liu (2008), working on a sample of farmers in China, reports however mixed evidence of using self-reported attitude as a predictor of risk preferences. In her work, the self-reported attitude appears to be a significant predictor of the individual loss aversion coefficient but it is not significant for explaining the elicited risk aversion.

${ }^{14}$ The Kornbrot test is based on the Wilcoxon matched-pairs signed-ranks test which can be used if data are distributed non-normally. It allows testing the equality of distributions for matched pairs of observations where the data are ordinal.
} 
by the level of the payoff. This result is in line with Holt and Laury (2002) who find that individual behavior is largely unaffected when hypothetical payoffs are scaled up. Using the midpoint of each CRRA class ${ }^{15}$, the mean CRRA coefficient is equal to 0.14 and 0.36 respectively for a low and a high payoff. Using the Holt and Laury (2002) terminology, subjects appear to be on average risk-neutral for a low payoff and slightly risk-averse for a high one.

Figure 1 plots the proportion of subjects that choose the safe choice for each decision for the adapted HL task, both for low and high payoffs. As one can see, the proportion of subjects choosing the safe option A falls as the probability of the higher payoff increases. The average numbers of "safe" choices (option A) are 4.2 and 3.7, respectively for low and high payoffs.

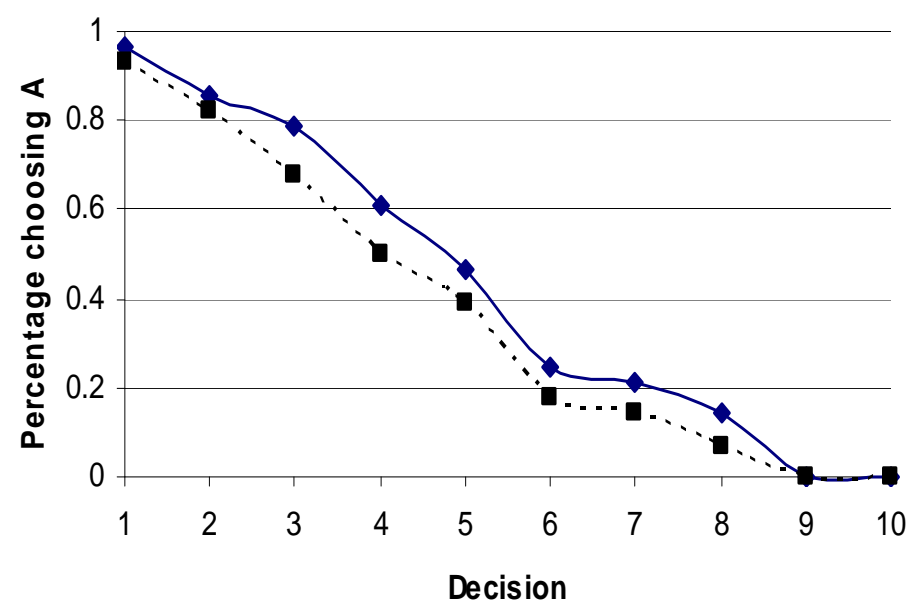

$\longrightarrow$ Holt \& Laury low ....... Holt \& Laury high

Figure 1: Proportion of safe choices in each decision (HL experiment)

The distribution of risk preference appears to be much more dissymmetric using the EG task than using the HL one. For low payoffs, $75 \%$ of subjects are classified as risk-averse. ${ }^{16}$ The percentage reaches $89 \%$ for high payoffs. Moreover, based on a Kornbrot test we find that the distribution of subjects across risk classes with low and high payoffs are statistically different $(\mathrm{p}<0.01)$. Using the midpoint of each CRRA class, the mean CRRA coefficient is equal to 0.62 and 1.02 respectively for a low and a high payoff. Using the Holt and Laury (2002) terminology, subjects appear to be on average risk averse for low payoffs and highly risk-averse for high ones.

\footnotetext{
${ }^{15}$ For the RA5 and the RL3 classes, we use 2 and -2 as class midpoints.

${ }^{16}$ One may attribute this result to the fact that the EG experiment includes a gamble without any risk whereas all binary lotteries in the HL task are risky. However, compared to Eckel and Grossman (2008), we still find a higher proportion for extreme classes (high risk aversion or high risk seeking attitudes).
} 
Discussion First, we do find a payoff effect affecting risk preference estimates. For a given task (HL or EG), the mean CRRA coefficient is significantly higher in the high payoff case. Secondly, we do find a task effect. Farmers appear to be on average significantly more risk averse in the EG task. Third, our CRRA coefficient estimates for French farmers are consistent with the existing literature dealing with risk preferences of farmers. For instance, in his classic study on Indian farmers, Binswanger (1980) find moderate to high CRRA parameters especially for high-stakes gambles (above 0.32). More recently, Liu (2008) reports an average CRRA coefficient for Chinese farmers equal to 0.71. Our estimates are also in line with risk preferences elicited on a wider population. Working on a representative sample of the Danish population, Andersen et al. (2010) find for instance that the mean CRRA coefficient in the field sample is 0.63 (with a $95 \%$ confidence interval between -0.49 and 1.87 ), while the mean coefficient is 0.79 in the laboratory sample (with a $95 \%$ confidence interval between -0.02 and 1.85$)$.

\subsection{Domain-Specific Risk-Taking (DOSPERT) assessment}

In Table 4, we report the results of the DOSPERT questionnaire. The risk-taking scale (which ranges from 6 to 42) evaluates behavioral intentions, that is, the likelihood with which respondents might engage in risky behaviors originating from five domains of life (ethical, financial, health/safety, social, and recreational risks). A low score for a specific context corresponds to a low willingness to take risks (risk averse behavior). On the contrary, a high score corresponds to a high willingness to take risks (risk seeker behavior).

First, the internal consistency estimates (i.e., Cronbach's alphas) associated with the domain risk-taking scores ranged from 0.63 to 0.87 , and they are similar to the values obtained originally by Blais and Weber (2006). ${ }^{17}$ Second, the risk attitude of respondents varies across domains. This result is in line with the literature in psychology that has shown that there are in fact multiple ways in which characteristics of the decision maker and/or the situation can affect choices under risk. Apparent risk taking by the same person in two situations might differ, for example, because the decision maker perceives the risks and benefits to differ in magnitude in the two domains (e.g., in a recreational vs. a financial decision). In our study subjects appear to be very risk averse for ethical and financial matters. If a high level of risk aversion for the financial domain has been already documented (see MacCrimmon and Wehrung (1990) for instance), the low willingness to take risks in the ethical dimension is more surprising. Interestingly, the ranking of risk attitude

\footnotetext{
${ }^{17}$ The Cronbach's alpha is a measure of the internal consistency of a score. It is equal to 0 if all questions entering into the score computation are independent and 1 if on contrary all questions are perfectly correlated. To be fully satisfying, one usually consider that the Cronbach's alpha must be greater than 0.7.
} 
Table 4: Domain-Specific Risk-Taking (DOSPERT) scores and correlations for risk-taking

\begin{tabular}{|c|c|c|c|c|c|c|}
\hline & Global & Ethical & Financial & Health/Safety & Recreational & Social \\
\hline Mean score & 19.66 & 11.14 & 16.93 & 21.39 & 19.07 & 29.79 \\
\hline St. dev. & 4.83 & 4.91 & 6.09 & 7.10 & 8.51 & 6.38 \\
\hline Cronbach's $\alpha$ & 0.87 & 0.63 & 0.63 & 0.70 & 0.74 & 0.66 \\
\hline & Global & Ethical & Financial & Health/Safety & Recreational & Social \\
\hline Global & 1.00 & & & & & \\
\hline Ethical & $0.74^{* * *}$ & 1.00 & & & & \\
\hline Financial & $0.70 * * *$ & $0.45^{* *}$ & 1.00 & & & \\
\hline Health/Safety & $0.59^{* * *}$ & 0.27 & 0.28 & 1.00 & & \\
\hline Recreational & $0.78^{* * *}$ & $0.68^{* * *}$ & $0.50^{* * *}$ & 0.28 & 1.00 & \\
\hline Social & $0.67^{* * *}$ & $0.36^{*}$ & $0.48^{* * *}$ & $0.39^{* *}$ & $0.33^{*}$ & 1.00 \\
\hline \multicolumn{7}{|c|}{$\begin{array}{l}\text { Minimum and maximum scores are } 6 \text { (lowest willingness to take risks) and } 42 \text { (highest willingness } \\
\text { to take risks), respectively. }\end{array}$} \\
\hline \multicolumn{7}{|c|}{$\begin{array}{l}\text { Correlations are based on individual DOSPERT scores reported on the } 7 \text { point scale where } 1 \\
\text { indicates that it is not at all likely that the individual will adopt the specified behavior and } \\
\text { where } 7 \text {, on contrary, indicates that the individual will adopt it for sure. }\end{array}$} \\
\hline
\end{tabular}

across domains is however similar to the one obtained by Blais and Weber (2006) on a sample of French respondents. Lastly, the second part of Table 4 shows that most of the pairwise correlations across DOSPERT scores are large and highly significant. A high willingness to take risks in one domain is associated with a high willingness to take risk in another one. This suggests the existence of a stable, underlying risk trait as found by Dohmen et al. (2009).

\subsection{Subjective assessment of risk attitude}

Mean responses for each context-specific question and correlations are reported in Table 5. The results suggest that the self evaluation attitudes slightly depend upon the context. The ranking of mean risk attitudes (from low risk toward high risk) is as follows: financial, health, global, professional. Dohmen et al. (2009) have conducted a similar analysis considering six possible contexts (general, career, sports and leisure, car driving, health and financial matters). Very interestingly, they report that the lowest individual willingness to take risk is found for financial matters and for health. The highest level of risk taking correspond to decisions related to the professional life. $64 \%$ of the farmers consider their professional behavior as being between risky and more than extremely risky. The percentage drops to $45 \%$ and $39 \%$ respectively for the health and the financial domains. One possible explanation could be that our subjects (farmers) are used to managing risks in their 
Table 5: Self evaluation of risk attitudes by domain and correlations across domains

\begin{tabular}{|c|c|c|c|c|}
\hline & Global & Professional & Financial & Health \\
\hline Mean self evaluation & 4.71 & 4.96 & 4.25 & 4.53 \\
\hline St. dev. & 1.08 & 1.23 & 1.71 & 1.73 \\
\hline Global & 1.00 & & & \\
\hline Professional & $0.38^{* *}$ & 1.00 & & \\
\hline Financial & $0.34^{*}$ & $0.32^{*}$ & 1.00 & \\
\hline Health & $0.55^{* * *}$ & $0.36^{*}$ & $0.32^{*}$ & 1.00 \\
\hline
\end{tabular}

professional life (either production risks such as climatic conditions or market risks). Hence, they may be more willing to take some risks. Another explanation could be that farmers can be classified as entrepreneurs, a category known to have specific risk preferences as discussed in Sarasvathy et al. (1998). On important consequence is that a measure of risk attitude in the context of financial risks should be taken with caution for being used directly in the context of a professional decision.

The second part of Table 5 demonstrates that risk attitudes are not perfectly correlated across contexts. However, the pairwise correlations are large and all are highly significant. This is suggestive of a stable, underlying risk trait. This result is in line with the findings of Dohmen et al. (2009).

\section{$5 \quad$ Stability of risk attitude measures across elicitation techniques}

In this section, we analyze the consistency of risk attitude measures across the different elicitation techniques we have used (experimental tasks, psychological questionnaire and self evaluation).

\subsection{Stability of risk attitude across lottery tasks}

First, we compare the risk preferences elicited through the HL and the EG experiments in order to identify a possible task effect. Second, we use our data to distinguish subjects who are attributed consistent risk preferences across tasks ${ }^{18}$, and we relate the stability of risk preferences to some observable characteristics of subjects.

First, we do find a task effect on the subjects risk preference measures. The average CRRA

\footnotetext{
${ }^{18}$ Preferences are consistent or stable across tasks if CRRA classes obtained with the HL of the EG tasks are the same.
} 
estimates are significantly greater with the EG experiments than with the HL ones. Moreover, using Kornbrot tests, we find that the distribution of subjects across risk classes obtained by the HL task and by the EG task are statistically different $(\mathrm{p}<0.05)$ both for low and high payoffs. ${ }^{19}$ Figure 2

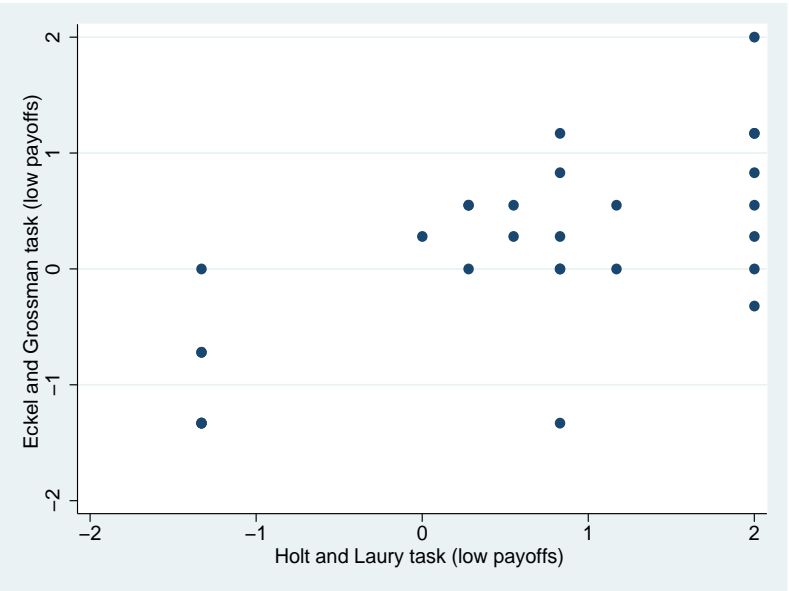

(a) Low payoffs

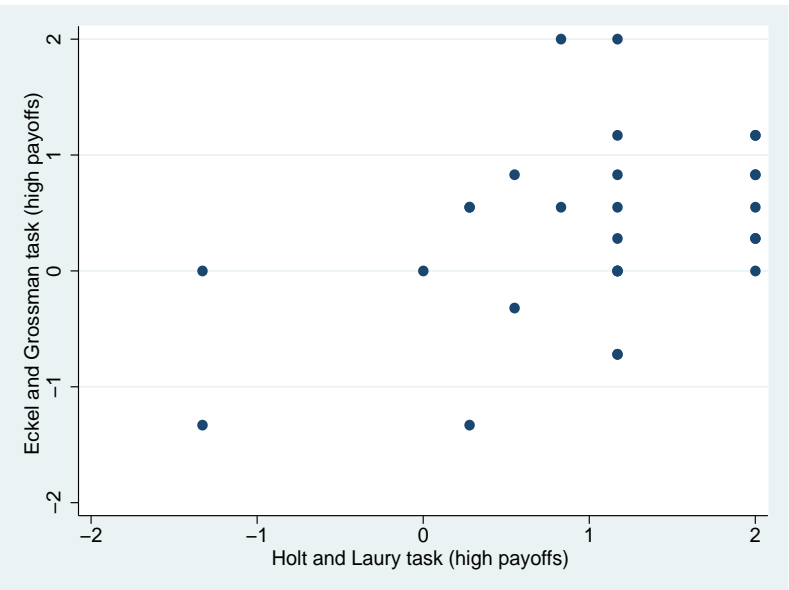

(b) High payoffs

Figure 2: Subjects CRRA centroides using adapted HL and EG tasks

provides a scatter plot of the CRRA centroides obtained by the HL task and by the EG task. If the risk preferences were exactly the same using the two elicitation techniques, all observations should lay on the 45 degree line. This is not the case, even though the observations are not located too far away from this line. Only $20.4 \%$ and $11.7 \%$ of subjects appear to have stable risk preferences respectively, for low and high payoffs. However, if we count subjects falling within one CRRA class higher or lower in each task, stability of preferences is observed with low and high payoffs respectively in $57.1 \%$ and $39.3 \%$ of the cases.

It should however be noticed that attitudes towards risk are significantly correlated across elicitation techniques. The correlation between the CRRA coefficients obtained using the HL and the EG tasks are respectively 0.40 (p-value $=0.0317)$ and 0.67 (p-value $=0.0001)$ for low and high payoffs. Using simple OLS, we have regressed the CRRA centroides obtained by the HL tasks on the CRRA centroides obtained by the EG tasks. The coefficients are significant at $1 \%$ both for low and high payoff cases ( 0.78 and 0.57 respectively). This result indicates that risk preference ranking seems to be preserved across tasks.

We do observe a task effect but elicited risk preferences appear to be more stable than what has

\footnotetext{
${ }^{19}$ Another explanation of this result would be that farmer's are not characterized by CRRA utility functions as assumed here.
} 
been reported in the existing literature. Hence, our results slightly differ from the previous literature which has usually found that the degree of risk aversion of an individual may vary across elicitation techniques. ${ }^{20}$ One possible explanation for explaining our findings is that our individual sample (French farmers) is more homogeneous in terms of socioeconomic characteristics than the samples used in previous studies. Moreover, farmers are used to take decisions in a context of uncertainty. This may reduce the cognitive burden of the lottery tasks. To more formally address the question of identifying the determinants of risk preference stability, we use a simple discrete choice model where the endogenous variable is a dummy variable equal to one if preferences are stable across the two tasks.

Table 6: Results of Logit model explaining preference stability across tasks

\begin{tabular}{lcc}
\hline Variable & Coefficient & (Std. Err.) \\
\hline Age & $0.167^{*}$ & $(0.101)$ \\
Children & 0.981 & $(0.744)$ \\
Other activity & $-2.659^{* *}$ & $(1.221)$ \\
Education + & -0.565 & $(1.277)$ \\
Low payoff & 1.076 & $(0.881)$ \\
Size+ & -2.515 & $(1.651)$ \\
Average CRRA class & 0.319 & $(0.243)$ \\
Intercept & $-11.385^{* *}$ & $(5.736)$ \\
\hline Age: age of the subject & \\
Children: number of children & \\
Other activity: dummy if the subject has a secondary professional activity \\
Education+: dummy if education level beyond secondary school \\
Low payoff: dummy for tasks with low payoffs \\
Size+: dummy for large farm (>180ha) \\
Average CRRA class: average CRRA class obtained using HL and EG tasks \\
$* * * * *, *$ for significant at 10,5,1\% respectively. \\
Pseudo R2: 0.25.
\end{tabular}

In Table 6, we report the results of a Logit model use for explaining preference stability across tasks. Older subjects tend to have more stable preferences than the rest of the sample. Subjects having a secondary professional activity have more instable preferences. The level of education does not seem to have a significant impact on the stability of preferences. This means that the argument of cognitive difficulty more easily addressed by more educated subjects is not an explanation of preference instability. The average CRRA class has a positive impact on the preference stability: risk loving subjects have more stable preferences than the rest of the sample. One should however be careful with this interpretation since the coefficient associated to the average CRRA class is not

\footnotetext{
${ }^{20}$ Isaac and James (2000) find that risk attitudes differ between first price auctions and the Becker-DeGrootMarschak procedure. Dave et al. (2007) report that the EG mechanism and the HL task give significantly different estimates.
} 
significantly different from zero.

\subsection{Experimental tasks, self-evaluation and psychological questionnaire}

The recent work by Deck et al. (2008) has suggested that the instability of risk preferences across experimental tasks could be related to the fact that risk attitudes may vary depending on the context. In this paragraph, we explore this possible explanation by analyzing the consistency between CRRA estimates from the lottery tasks, DOSPERT scores and self evaluation of risk preferences.

Table 7: Risk attitude Spearman's rank correlations across elicitation methods

\begin{tabular}{|c|c|c|c|c|c|c|c|c|c|c|}
\hline & \multicolumn{6}{|c|}{ DOSPERT scores } & \multicolumn{4}{|c|}{ Subjective assessment } \\
\hline & Gen. & Eth. & Fin. & $\mathrm{H} \& \mathrm{~S}$ & Recr. & Soc. & Gen. & Prof. & Fin. & Health \\
\hline HL low payoffs & -0.06 & $-0.26^{*}$ & 0.15 & -0.22 & 0.03 & -0.14 & 0.01 & -0.28 & 0.15 & 0.02 \\
\hline HL high payoffs & $0.33^{*}$ & 0.10 & $0.26^{*}$ & -0.07 & $0.27^{*}$ & 0.22 & 0.18 & -0.11 & 0.09 & 0.09 \\
\hline EG low payoffs & 0.30 & 0.21 & $0.32^{*}$ & -0.04 & $0.35^{*}$ & 0.16 & 0.01 & -0.01 & $0.41^{* *}$ & 0.09 \\
\hline EG high payoffs & $0.40^{*}$ & 0.18 & $0.28^{*}$ & 0.15 & $0.45^{* *}$ & 0.25 & 0.07 & $0.33^{*}$ & $0.42^{* *}$ & $0.34^{*}$ \\
\hline
\end{tabular}

$* * *, * *, *$ for significant at $10,5,1 \%$ respectively.

In Table 7, we report the Spearman's rank correlation coefficients between the CRRA classes obtained with the two types of lotteries (HL and EG) on one hand, and the DOSPERT scores and the subjective assessment on the other hand.

We first find that the HL measures of risk preferences are only very slightly correlated with the DOSPERT scores or with the subjective assessment of individuals. In case of low payoffs, the CRRA class is only significantly correlated with the ethical DOSPERT score but the correlation appears to be negative. In case of high payoffs, the CRRA class is significantly correlated with the DOSPERT scores corresponding to the financial and the recreational dimensions, and also with the global score. The Spearman's rank correlation coefficients between the EG measures of risk preferences and the DOSPERT scores or the subjective assessment appear to be higher. The DOSPERT score corresponding to the financial and the recreational dimensions are significantly correlated with the EG measure of risk preferences, both in the case of low and high payoffs. The subjective assessment for the financial domain are significantly correlated with the EG measure of risk preferences, both in the case of low and high payoffs. Interestingly, in case of high payoffs the EG measure of risk preferences appears to be significantly correlated with the subjective assessment for the professional domain.

Our results are in line with previous studies showing that the risk attitude elicited through 
lotteries often correlates with risk attitude towards investments. Deck et al. (2008) demonstrate for instance that the more willing a person is to invest income in a very speculative stock, the less risk averse he will appear as measured by the Holt and Laury task.

\subsection{Self-evaluation and psychological questionnaire}

In this paragraph, we analyze the consistency of risk preferences obtained with the psychological questionnaire and with the subjective assessment.

Table 8: Spearman's rank correlations between DOSPERT scores and Subjective assessments

DOSPERT scores

\begin{tabular}{lllllll} 
& Global & Ethical & Financial & H\&S & Recreational & Social \\
\hline & & & & & & \\
Sub. Ass. Global & $0.36^{*}$ & 0.20 & $0.40^{* *}$ & 0.07 & 0.10 & $0.44^{* *}$ \\
Sub. Ass. Professional & $0.34^{*}$ & 0.12 & 0.28 & 0.29 & $0.31^{*}$ & $0.37^{* *}$ \\
Sub. Ass. Finance & 0.28 & 0.05 & $0.54^{* * *}$ & 0.09 & 0.11 & 0.31 \\
Sub. Ass. Health & $0.63^{* * *}$ & 0.29 & $0.46^{* * *}$ & $0.57^{* *}$ & $0.40^{* *}$ & $0.37^{*}$
\end{tabular}

$* * *, * *, *$ for significant at $10,5,1 \%$ respectively.

Table 8 reports the Spearman's rank correlation coefficients between the DOSPERT scores and the subjective assessment of risk attitude. The correlation between the global measure of risk preferences provided by the two approaches is high and significant at 10\%. Interestingly, the DOSPERT score for the financial domain is highly correlated with the subjective assessment of individuals for the finance domain. The same result is found for the health domain. Those evidences suggest that relying on subjects to give an assessment of their willingness to take risks is a simple but reliable way to elicit some measure of risk attitudes across contexts. Our result is in line with the recent work by Dohmen et al. (2009) who find that a simple, qualitative survey measure can generate a meaningful measure of risk attitudes, which maps into actual choices in lotteries with real monetary consequences.

\subsection{Analyzing the determinants of risk attitudes}

As demonstrated by Deck et al. (2008), individual differences may help explain the apparent within-subject inconsistency between different behavioral measures of risks. This is the assumption we test by assessing if some observed characteristics of the respondent (personality or socioeconomic characteristics) have a significant impact on the estimates risk attitudes.

In Table 9, we report the results of the interval regressions for the CRRA classes obtained with the HL and the EG lotteries. By using interval regressions, we specify the dependent variable as a 
Table 9: Interval regressions for CRRA classes

\begin{tabular}{|c|c|c|c|c|c|c|c|c|}
\hline & \multicolumn{4}{|c|}{ Eckel and Grossman task } & \multicolumn{4}{|c|}{ Holt and Laury task } \\
\hline & \multicolumn{2}{|c|}{ low payoffs } & \multicolumn{2}{|c|}{ high payoffs } & \multicolumn{2}{|c|}{ low payoffs } & \multicolumn{2}{|c|}{ high payoffs } \\
\hline & Coef. & Std. Err. & Coef. & Std. Err. & Coef. & Std. Err. & Coef. & Std. Err. \\
\hline Age & -0.040 & 0.042 & -0.017 & 0.022 & -0.019 & 0.020 & $-0.049^{* * *}$ & 0.017 \\
\hline Children & 0.375 & 0.366 & $0.408^{* *}$ & 0.194 & 0.127 & 0.179 & -0.116 & 0.146 \\
\hline Education + & -0.612 & 0.823 & -0.329 & 0.430 & -0.106 & 0.406 & $-0.713^{* *}$ & 0.329 \\
\hline Income & -0.556 & 0.680 & 0.104 & 0.324 & $-0.604^{*}$ & 0.329 & -0.144 & 0.243 \\
\hline Intercept & 8.426 & 8.074 & 0.042 & 3.889 & $7.759^{* *}$ & 3.921 & 4.621 & 2.919 \\
\hline $\begin{array}{l}\text { Age: age of th } \\
\text { Children: nun } \\
\text { Education }+ \text { : } \\
\text { Income: farm } \\
* * * * * * \text { for si }\end{array}$ & $\begin{array}{l}\text { subject } \\
\text { ber of ch } \\
\text { ummy if } \\
\text { evel proc } \\
\text { nificant }\end{array}$ & $\begin{array}{l}\text { ildren } \\
\text { education } \\
\text { luction valu } \\
\text { at } 10.5 \text { anc }\end{array}$ & $\begin{array}{l}1 \text { beyon } \\
\text { f the pr } \\
\text { respec }\end{array}$ & $\begin{array}{l}\text { condary } \\
\text { us year } \\
\text { ely. }\end{array}$ & uros) & & & \\
\hline
\end{tabular}

range defined by the subject's lower and upper bounds of the risk preference parameter. As a result it allows to account for cases where the data are right or left-censored (e.g., the range is bounded by infinity). As potential determinants, we include the age of the respondent (Age), the number of children (Children), the level of education (Education+) and the respondent income (Income).

Globally, the predictive power of the models is relatively low, especially in the case of low payoffs however the signs of the variables make sense. Being older results in more risk-seeker behaviors for all lotteries. The relationship between age and risk preference is however significant only for the HL task with high payoffs. Respondents having a lot children tend to be much more risk averse. Hence, the coefficient associated to (Children) is positive in all cases but significantly different from zero only in the EG task with high payoffs. A high level of education and a high level of income is associated to risk seeking behaviors. Notice that we cannot test for a gender effect since our sample is exclusively made of men.

\section{Conclusion}

There has been a recent surge in research to bring laboratory experiments to field subjects in order to complement the main conclusions obtained in traditional laboratory experiments. Although field experiments can be viewed as less controlled variants of a laboratory experiment, they may appear relevant for some research domains like elicitation of preferences and beliefs. Indeed, it can be important to have non-standard subjects (bankers, entrepreneurs, farmers, etc.) first because elicitated preferences can then be compared to real choices made by individuals and second, because non-standard subjects may be endowed with past experiences affecting their preferences. Moreover, if the research is domain-specific (as it is clearly the case here), it is also important to consider 
subjects that are directly affected by the domain.

In this paper, we have contributed to the literature on risk preference stability by comparing different elicitation procedures on the same sample of non-standard subjects. Our sample is made of 30 French farmers having completed three types of elicitation tasks: two multiple price list choices based on the Holt and Laury and on the Eckel and Grossman experiments, a risk-taking psychological questionnaire initially proposed by Weber et al. (2002) dealing with risk behavior in five domains (health and safety, social, ethical, financial, recreational) and a self-evaluation of risk preferences in four domains (general, professional, finance, health). We have then compared farmer risk attitudes elicited through the various elicitation methods.

The main empirical results are the following. First, within the class of lottery choice tasks, risk preference evaluations are affected by the experimental framework, even if attitudes towards risk are significantly correlated across elicitation techniques. Responses to the Holt and Laury's format indicate a lower risk aversion than responses with the Eckel and Grossman's format. However, risk preference ranking remains stable across tasks. Some robust results for the population of interest have been obtained. For instance, a majority of farmers appear to be risk averse and risk aversion is particularly high in case of high payoffs. Second, we provide some evidences on the fact that risk preferences are context-dependent. Using the the psychological questionnaire, we find that the risk attitude measures elicited through traditional experiments often correlate with risk attitude towards

investments. It appears that subjects view the traditional task as an investment. For instance, in the psychological questionnaire the more likely a subject is willing to invest "income in a moderate growth mutual fund", the more risk averse she will appear using by both the Holt and Laury's experiment or the Eckel and Grossman's experiment. Lastly, we observe a significant correlation between the self evaluation of risk attitude and the measures provided by the lottery choices and by the psychological questionnaire. This result suggests that a simple qualitative self-reported measure can generate a meaningful evaluation of risk attitudes, which maps into actual choices in lotteries tasks.

\section{References}

Andersen, S., G. W. Harrison, M. I. Lau, and E. E. Rutström (2008): "Lost in state space: Are preferences stable?," International Economic Review, 49(3), 1091-1112.

Andersen, S., G. W. Harrison, M. I. Lau, and E. E. Rutström (2010): "Preference heterogeneity in experiments: Comparing the field and laboratory," Journal of Economic Behavior \& 
Anderson, L. R., And J. M. Mellor (2008): "Are Risk Preferences Stable? Comparing an Experimental Measure with a Validated Survey-Based Measure," College of William and Mary Department of Economics, Working Paper Number 74, (August).

Berg, J., J. Dickhaut, and K. MCCabe (2005): "Risk preference instability across institutions: A dilemna," Proceedings of the National Academy of Sciences, 201(11), 4209-4214.

Binswanger, H. P. (1980): "Attitudes toward Risk: Experimental Measurement in Rural India," American Journal of Agricultural Economics, 62(3), 395-407.

Blais, A.-R., and E. U. Weber (2006): "A Domain-Specific Risk-Taking (DOSPERT) scale for adult populations," Judgment and Decision Making, 1(1), 33-47.

Bruner, D. D. (2009): "Changing the Probability Versus Changing the Reward," Working Paper, Appalachian State University.

Dave, C., C. Eckel, C. Johnson, and C. Rojas (2007): "Eliciting Risk Preferences: When is Simple Better," Working Paper, University of Texas at Dallas.

Deck, C., J. Lee, J. Reyes, and C. Rosen (2008): "Measuring Risk Attitudes Controlling for Personality Traits," Working paper, University of Arkansas.

Dohmen, T., A. Falk, D. Huffman, U. Sunde, J. Schupp, and G. Wagner (2009): "Individual Risk Attitudes: Measurement, Determinants and Behavioral Consequences," Forthcoming in the Journal of the European Economic Association.

Eckel, C., And P. Grossman (2002): "Sex Differences and Statistical Stereotyping in Attitudes Toward Financial Risk," Evolution and Human Behavior, 23(4), 281-295.

ECkel, C. C., And P. J. Grossman (2008): "Forecasting risk attitudes: An experimental study using actual and forecast gamble choices," Journal of Economic Behavior 83 Organization, 68(1), $1-7$.

HARRISON, G. (2006): Hypothetical bias over uncertain outcomesUsing experimental methods in environmental and resource economics. J.A. List (Ed.), Northampton, MA: Edward Elgar, pp. 41-69.

HARRison, G., AND J. List (2004): "Field experiments," Journal of Economic Literature, 42, $1013-1059$. 
Holt, C. A., And S. K. Laury (2002): "Risk Aversion and Incentive Effects," The American Economic Review, 92(5), 1644-1655.

Hopfensitz, A., M. Krawczyk, and F. van Winden (2007): "Investment, Resolution of Risk, and the Role of Affect," CEPR DP6822 Working Paper, University of Texas at Dallas.

IsAaC, R., And D. James (2000): "Just Who Are You Calling Risk Averse?," Journal of Risk E Uncertainty, 20(2), 177-187.

Ivanova-Stenzel, R., And T. C. Salmon (2004): "Bidder Preferences Among Auction Institutions," Eeonomic Inquiry, 42(2), 223-236.

— (2008): "Robustness of Bidder Preferences Among Auction Institutions," Economic Inquiry, 46(3), 355-368.

Kachelmeier, S. J., and M. Shehata (1992): "Examining Risk Preferences Under High Monetary Incentives: Experimental Evidence from the People's Republic of China," The American Economic Review, 82(5), 1120-1141.

Kinlstrom, R. E., and J.-J. LAffont (1979): "A General Equilibrium Entrepreneurial Theory of Firm Formation Based on Risk Aversion.," Journal of Political Economy, 87(4), 719.

Koundouri, P., M. Laukkanen, S. Myyrä, and C. Nauges (2009): "EU Agricultural Policy Change: Effects on Farmers' Risk Attitudes," European Journal of Agricultural Economics, 36, $53-77$.

LiU, E. (2008): "Time to Change What to Sow: Risk Preferences and Technology Adoption Decisions of Cotton Farmers in China," Working paper 526, Princeton University, Industrial Relations Sections.

MacCrimmon, K. R., and D. A. Wehrung (1990): "Characteristics of Risk Taking Executives," Management Science, 36, 422-435.

Quizon, J. B., H. P. Binswanger, and M. J. Machina (1984): "Attitudes Toward Risk: Further Remarks," The Economic Journal, 94(373), 144-148.

Reynaud, A., S. Couture, J. Duruy, and J.-E. Bergez (2009): "Farmer's Risk Attitude: Reconciliating Stated and Revealed Preference Approaches," Mimeo, University of Toulouse 1. 
Sarasvathy, D. K., H. A. Simon, and L. Lave (1998): "Perceiving and managing business risks: differences between entrepreneurs and bankers," Journal of Economic Behavior $\&$ Organization, $33(2), 207-225$.

Schommaker, P. J. H. (1990): "Are risk preferences related across payoff domains and response modes?," Management Science, 36.

Tanaka, T., C. Camerer, and Q. Nguyen (2009): "Poverty, politics, and preferences: Field experiments and survey data from Vietnam," The American Economic Review, Forthcoming.

Weber, E. U., A.-R. Blais, and N. E. Betz (2002): "A Domain-specific Risk-attitude Scale: Measuring Risk Perceptions and Risk Behaviors," Journal of Behavioral Decision Making, 15, 263-290. 


\section{A Experimental protocol for risk preference elicitation}

We employ two experimental Multiple Price List (MPL) procedures for eliciting attitudes towards risk, based on Holt and Laury (2002) and on Eckel and Grossman (2002). We also use a risk-taking psychological questionnaire, and a series of risk preference self-evaluation questions. All subjects have voluntarily participated to the four treatments of the experience.

In the first treatment, called the Holt and Laury's treatment, subjects were provided with a series of binary choices for two tasks. The first task involved ten sequential choices between risky lotteries in the domain of gains. The second task is similar except that all payoffs have been multiplied by twenty.

In the second treatment, called the Eckel and Grossman's treatment, subjects had to complete two tasks. In each task, the subject had to select a preferred lottery between 9 possible ones. All lotteries had different levels of payoffs but the same probabilities. The second task is similar except that all payoffs were been multiplied by twenty.

In the third treatment, called the psychological questionnaire, subjects complete the DOSPERT test Weber, Blais, and Betz (2002) modified by Blais and Weber (2006)). This psychological questionnaire contains thirty items allowing to assess the likelihood of adopting a risky behavior in five different domains (health and safety, social, ethical, financial, recreational). For each item, subjects are asked to rate their behavior with respect to the risky activity described. Specifically, subjects report how likely they are to engage in a certain risk-related activity on a nine-point rating scale ranging from 1 ("Not at all likely") to 9 ("Certain"). These questions provide us with a psychometric measure of individual risk attitude for the five different domains.

Finally, in the fourth treatment, subjects were required to complete a series of four questions concerning their self-evaluation of risk attitudes. For each question, subjects report how they consider their behavior and decision as risky on a nine-point scale ranging from 1 ("Not at all risky") to 9 ("More than extremely risky"). 


\section{B Experimental protocol}

In this Appendix, we present the instructions and the protocol we have used for eliciting risk preferences.

The first part presents the instructions read to each subject. It gives also the scoreless tasks that have been realized by each subject to insure a good comprehension of the protocol. The second part of this appendix presents the four tasks completed by each subject.

Notice that both the instructions and the different tasks have been translated from French to English.

\section{B.1 Instructions for risk elicitation tasks}

\section{Protocol principle}

Some decisions taken by a farmer on his farm are linked to technical constraints. Some decisions are however very individual in the sense that they may result from specific objectives of the farmer. Among these objectives, we focus in this protocol on how you manage risks, either climate risk or risks associated with fluctuations in crop prices or input costs.

We know that individuals placed in similar risky context do not take the same decisions simply because they are not ready to take the same risks. We all know people that can be described as "prudent" and others for whom the adjective "risk-taker" is more appropriate.

The experience you will participate will allow us to better understand your behaviour vis-à-vis risk. The tests you will pass will then allow us to assess how you behave in risky situations.

In tests 1 and 2, we discuss situations of financial risks using "lotteries". These lotteries are used in economics in order to make people reveal their preferences for situations more or less.

However, we all know that the same individual may behave differently depending on the nature of risks. A farmer may have a "risky" behaviour for financial investments but may take much more "prudent" decision regarding its work. That's what we try to look at in the third test which will come in the form of a series of 30 questions. Some questions may seem strange or surprising, but this questionnaire has global coherence. We will qualitatively assess your attitude to risk in four domains:

- Ethical

- Financial

- Health

- Social

It is important to us that you answer all questions, while knowing that your answers will be treated anonymously and will remain completely confidential.

In the last test, we will ask you to evaluate your behaviour for different risks. This will allow us to see how your assessment differs from measurements obtained from the first three tests. 


\section{Setting of the protocol}

You'll need to answer several successive questions in four tests. We first present the type of questions you will need to respond.

\section{TEST 1: CHOICE OF LOTTERY}

\section{Objective}

In test 1 we consider situations of financial risks using "lotteries". These lotteries are used in economics in order to make people reveal their preferences for situations more or less risky. All questions relate to hypothetical situations for which we ask you to answer as if you were facing a real situation.

\section{Setting}

In test 1 , we offer 2 series of 9 lottery choice. For each row, two gains are possible (a low gain or a high gain) with identical probabilities. You are asked to enter your favourite row among the 9 by checking the appropriate box.

\begin{tabular}{|c|c|c|c|}
\hline Example & Gains & Probability & Your choice \\
\hline \multirow[t]{2}{*}{ Lottery 1} & $40 €$ & $50 \%$ & \\
\hline & $40 €$ & $50 \%$ & \\
\hline \multirow{2}{*}{ Lottery 2} & $32 €$ & $50 \%$ & \\
\hline & $51 €$ & $50 \%$ & \\
\hline \multirow{2}{*}{ Lottery 3} & $24 €$ & $50 \%$ & \\
\hline & $64 €$ & $50 \%$ & \\
\hline \multirow[t]{2}{*}{ Lottery 4} & $16 €$ & $50 \%$ & \\
\hline & $78 €$ & $50 \%$ & \\
\hline \multirow[t]{2}{*}{ Lottery 5} & $12 €$ & $50 \%$ & \\
\hline & $86 €$ & $50 \%$ & \\
\hline \multirow[t]{2}{*}{ Lottery 6} & $8 €$ & $50 \%$ & \\
\hline & $91,5 €$ & $50 \%$ & \\
\hline \multirow[t]{2}{*}{ Lottery 7} & $6 €$ & $50 \%$ & \\
\hline & $92,9 €$ & $50 \%$ & \\
\hline \multirow[t]{2}{*}{ Lottery 8} & $4 €$ & $50 \%$ & \\
\hline & $93,4 €$ & $50 \%$ & \\
\hline \multirow[t]{2}{*}{ Lottery 9} & $1 €$ & $50 \%$ & \\
\hline & $93,5 €$ & $50 \%$ & \\
\hline
\end{tabular}

For example, if you choose the 4 lottery, you have 50\% chance of winning 78 Euros and 50\% chance to win 16 Euros. 


\section{TEST 2: CHOICE OF LOTTERY}

\section{Objective}

In test 2 we also deal with situations of financial risks by "lottery".

\section{Setting}

During this test, we will propose several times two lotteries (Lottery A or Lottery B). Each time, you must indicate which of the 2 lotteries you prefer.

Note that there is no right or wrong answer. Your choice should really be guided by your preferences.

This test consists of 20 lottery choices divided into two independent parts.

\section{Example}

Which lottery do you prefer?

\section{Lottery A}

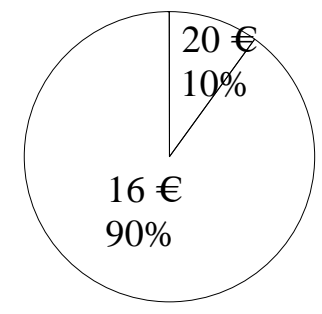

A

\section{Lottery B}

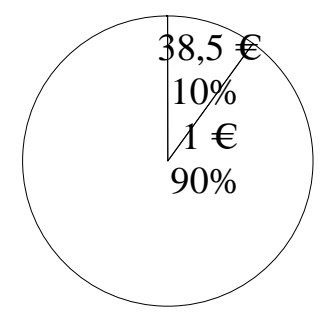

B

Please choose between Lottery A or Lottery B by checking A or B.

For example, if you choose Lottery A, you have 10\% chance of winning 20 Euros and $90 \%$ chance to win 16 Euros.

\section{TEST 3: PSYCHOMETRIC QUESTIONNAIRE}

\section{Objective}

This questionnaire will allow us to qualitatively assess your attitude for different types of risks (ethical, financial, health, social). Some questions may seem strange or surprising, but this questionnaire has global coherence. It is important to us that you answer all questions, while knowing that your answers will be treated anonymously and will remain completely confidential.

\section{Setting}

The test 3 includes 30 questions for which you must indicate your level of risk taking among 9 possible levels. 
For each statement asked, you must indicate the likelihood that you take part in the activity specified or you adopt the behaviour specified if you were in the situation described.

You must then choose one of the 9 options ranging from "Not at all likely" to "Certain" by using the scale.

\begin{tabular}{|c|c|c|c|c|c|c|c|c|}
\hline 1 & 2 & 3 & 4 & 5 & 6 & 7 & 8 & 9 \\
\hline Not at all likely & $\begin{array}{c}\text { Not } \\
\text { likely }\end{array}$ & $\begin{array}{c}\text { Very few } \\
\text { likely }\end{array}$ & $\begin{array}{c}\text { Slightly } \\
\text { likely }\end{array}$ & $\begin{array}{c}\text { Moderately } \\
\text { likely }\end{array}$ & likely & $\begin{array}{c}\text { Very } \\
\text { likely }\end{array}$ & Extremely likely & Certain \\
\hline & & & & & & & & \\
\hline
\end{tabular}

\section{Example}

Admitting that your tastes are different from those of a friend.

\begin{tabular}{|c|c|c|c|c|c|c|c|c|}
\hline 1 & 2 & 3 & 4 & 5 & 6 & 7 & 8 & 9 \\
\hline $\begin{array}{c}\text { Not at all } \\
\text { likely }\end{array}$ & $\begin{array}{c}\text { Not } \\
\text { likely }\end{array}$ & $\begin{array}{c}\text { Very few } \\
\text { likely }\end{array}$ & $\begin{array}{c}\text { Slightly } \\
\text { likely }\end{array}$ & $\begin{array}{c}\text { Moderately } \\
\text { likely }\end{array}$ & likely & $\begin{array}{c}\text { Very } \\
\text { likely }\end{array}$ & Extremely likely & Certain \\
\hline & & & & & & & & \\
\end{tabular}

Put a mark in the box corresponding to your behaviour.

\section{TEST 4: SUBJECTIVE ASSESSMENT OF ATTITUDE TOWARDS RISKS}

\section{Objective}

In the last test, we will ask you to evaluate subjectively your behaviour for different risks. This will allow us to see how your assessment differs from measurements obtained from the first three tests.

\section{Setting}

In test 4, we will ask you how you ti evaluate your behaviour and your attitude for different types of risk on a scale going from 1 (not at all risky) to 9 (extremely risky behaviour).

\section{Example}

In general, you would describe your behaviour and the decisions you make as:

\begin{tabular}{|c|c|c|c|c|c|c|c|c|}
\hline 1 & 2 & 3 & 4 & 5 & 6 & 7 & 8 & 9 \\
\hline $\begin{array}{c}\text { Not at all } \\
\text { risky }\end{array}$ & $\begin{array}{c}\text { Not } \\
\text { risky }\end{array}$ & $\begin{array}{c}\text { Very few } \\
\text { risky }\end{array}$ & $\begin{array}{c}\text { Slightly } \\
\text { risky }\end{array}$ & $\begin{array}{c}\text { Moderately } \\
\text { risky }\end{array}$ & Risky & $\begin{array}{c}\text { Very } \\
\text { risky }\end{array}$ & $\begin{array}{c}\text { Extremely } \\
\text { risky }\end{array}$ & $\begin{array}{c}\text { More than } \\
\text { Extremely risky }\end{array}$ \\
\hline & & & & & & & & \\
\hline
\end{tabular}

Put a cross in the box corresponding to your behaviour. 


\section{B.2 Beginning of the protocol}

\section{TEST 1: CHOICE OF LOTTERY}

In test 1 , we offer 2 series of 9 lottery choice. For each row, two gains are possible (a low gain or a high gain) with identical probabilities. You are asked to enter your favourite row among the 9 by checking the appropriate box.

Test 1. Q 1.

Put a mark for your preferred lottery

\begin{tabular}{|c|c|c|c|}
\hline & Gains & Probabilities & Your choice \\
\hline \multirow[t]{2}{*}{ Lottery 1} & $40 €$ & $50 \%$ & \\
\hline & $40 €$ & $50 \%$ & \\
\hline \multirow[t]{2}{*}{ Lottery 2} & $32 €$ & $50 \%$ & \\
\hline & $51 €$ & $50 \%$ & \\
\hline \multirow[t]{2}{*}{ Lottery 3} & $24 €$ & $50 \%$ & \\
\hline & $64 €$ & $50 \%$ & \\
\hline \multirow[t]{2}{*}{ Lottery 4} & $16 €$ & $50 \%$ & \\
\hline & $78 €$ & $50 \%$ & \\
\hline \multirow[t]{2}{*}{ Lottery 5} & $12 €$ & $50 \%$ & \\
\hline & $86 €$ & $50 \%$ & \\
\hline \multirow[t]{2}{*}{ Lottery 6} & $8 €$ & $50 \%$ & \\
\hline & $91,5 €$ & $50 \%$ & \\
\hline \multirow[t]{2}{*}{ Lottery 7} & $6 €$ & $50 \%$ & \\
\hline & $92,9 €$ & $50 \%$ & \\
\hline \multirow[t]{2}{*}{ Lottery 8} & $4 €$ & $50 \%$ & \\
\hline & $93,4 €$ & $50 \%$ & \\
\hline \multirow[t]{2}{*}{ Lottery 9} & $1 €$ & $50 \%$ & \\
\hline & $93,5 €$ & $50 \%$ & \\
\hline
\end{tabular}


Test 1. Q 2.

Put a mark for your preferred lottery

\begin{tabular}{|c|c|c|c|}
\hline & Gains & Probabilities & Your choice \\
\hline \multirow[t]{2}{*}{ Lottery 1} & $800 €$ & $50 \%$ & \\
\hline & $800 €$ & $50 \%$ & \\
\hline \multirow[t]{2}{*}{ Lottery 2} & $640 €$ & $50 \%$ & \\
\hline & $1020 €$ & $50 \%$ & \\
\hline \multirow[t]{2}{*}{ Lottery 3} & $480 €$ & $50 \%$ & \\
\hline & $1280 €$ & $50 \%$ & \\
\hline \multirow[t]{2}{*}{ Lottery 4} & $320 €$ & $50 \%$ & \\
\hline & $1560 €$ & $50 \%$ & \\
\hline \multirow[t]{2}{*}{ Lottery 5} & $240 €$ & $50 \%$ & \\
\hline & $1720 €$ & $50 \%$ & \\
\hline \multirow[t]{2}{*}{ Lottery 6} & $160 €$ & $50 \%$ & \\
\hline & $1830 €$ & $50 \%$ & \\
\hline \multirow[t]{2}{*}{ Lottery 7} & $120 €$ & $50 \%$ & \\
\hline & $1858 €$ & $50 \%$ & \\
\hline \multirow[t]{2}{*}{ Lottery 8} & $80 €$ & $50 \%$ & \\
\hline & $1868 €$ & $50 \%$ & \\
\hline \multirow[t]{2}{*}{ Lottery 9} & $20 €$ & $50 \%$ & \\
\hline & $1870 €$ & $50 \%$ & \\
\hline
\end{tabular}




\section{TEST 2: CHOICE OF LOTTERY}

During this test, we will propose several times two lotteries (Lottery A or Lottery B). Each time, you must indicate which of the two lotteries you prefer. Note that there is no right or wrong answer. Your choice should really be guided by your preferences.

This test consists of 20 lottery choices divided into two independent parts.

Choose your preferred lottery by putting a mark either on the « $\mathrm{A}$ » or the « $\mathrm{B}$ » box for each question.

$1^{\text {st }}$ Part: 10 questions

Test 2. Q 1. Choose you preferred lottery

\section{Lottery A}

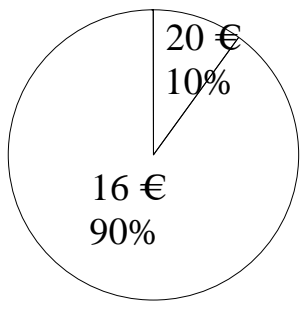

A

Test 2. Q 2. Choose you preferred lottery

Lottery A

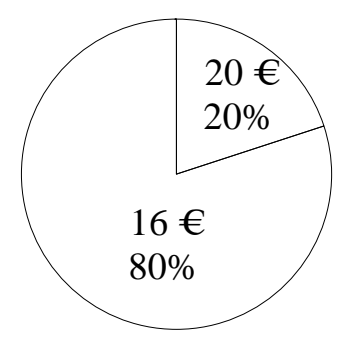

A

Test 2. Q 3. Choose you preferred lottery

Lottery A

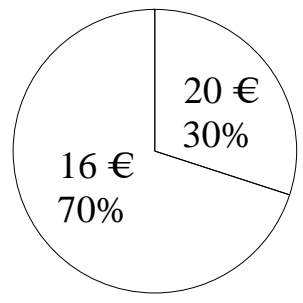

Lottery B

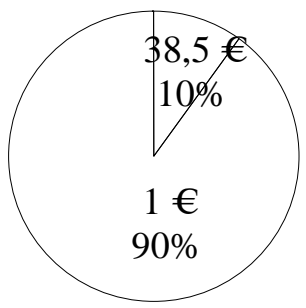

B

Lottery B

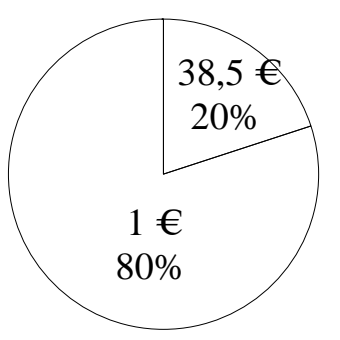

B

Lottery B

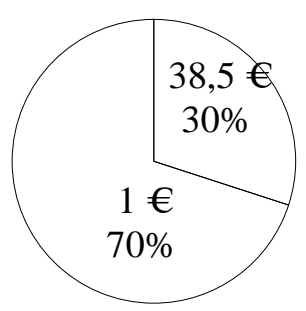


Test 2. Q 4. Choose you preferred lottery

Lottery A

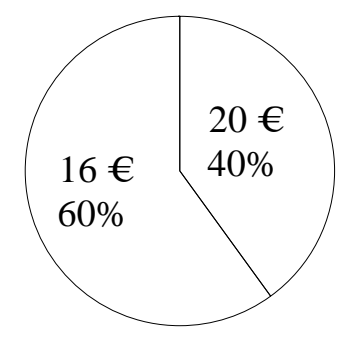

A

\section{Lottery B}

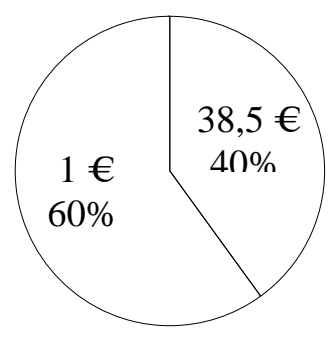

B

Lottery B

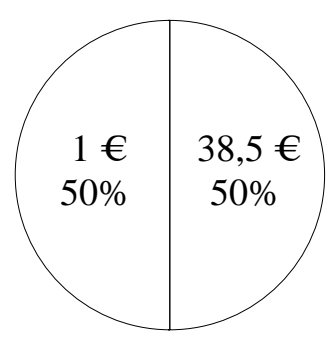

B

Test 2. Q 6. Choose you preferred lottery

\section{Lottery A}

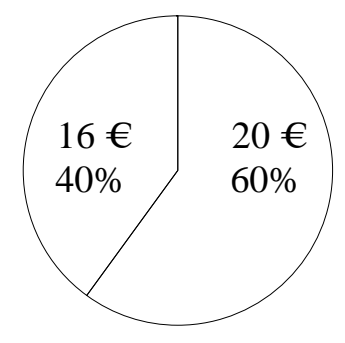

A

\section{Lottery B}

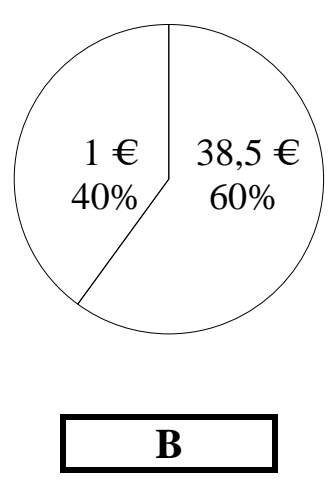


Test 2. Q 7. Choose you preferred lottery

\section{Lottery A}

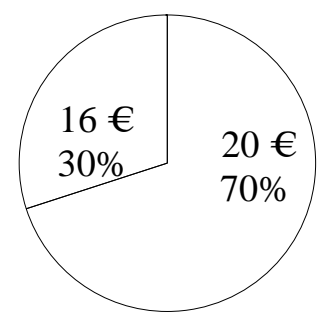

A
Lottery B

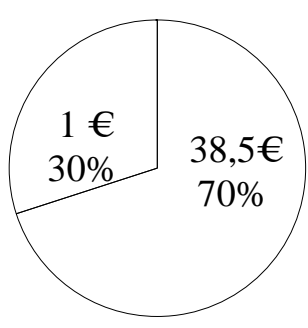

B

Test 2. Q 8. Choose you preferred lottery

\section{Lottery A}

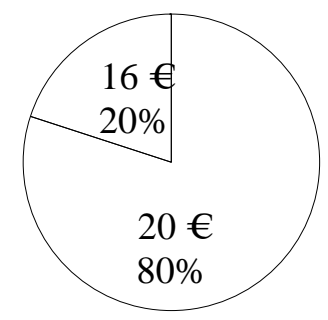

A

Test 2. Q 9. Choose you preferred lottery

\section{Lottery A}

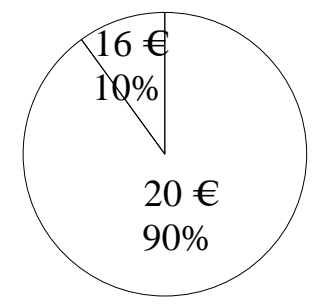

A

Lottery B

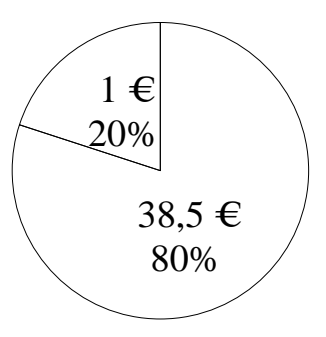

B

\section{Lottery B}

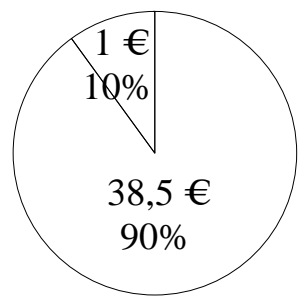

B 
Test 2. Q 10. Choose you preferred lottery

Lottery A

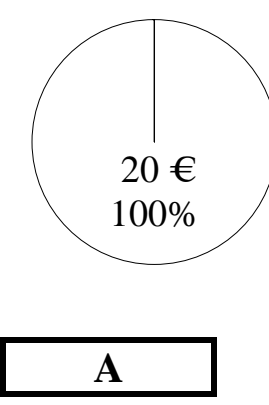

Lottery B

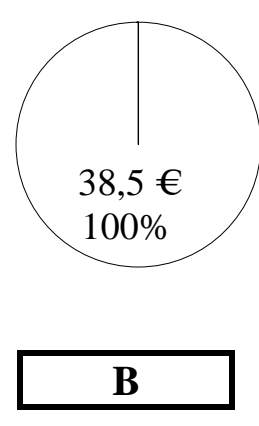


$2^{\text {nd }}$ Part: 10 questions

Test 2. Q 11. Choose you preferred lottery

Lottery A

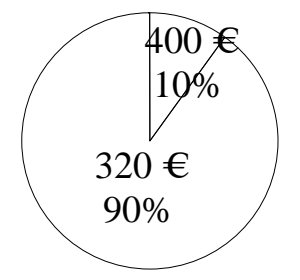

A
Lottery B

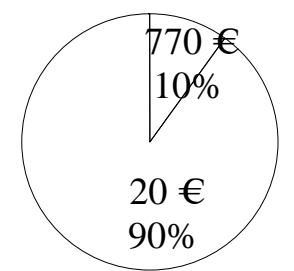

B

Test 2. Q 12. Choose you preferred lottery

\section{Lottery A}

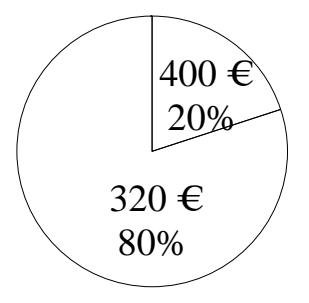

A

\section{Lottery B}

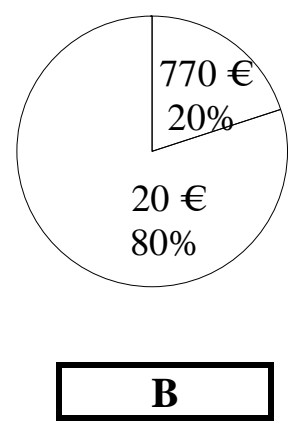

Test 2. Q 13. Choose you preferred lottery

\section{Lottery A}

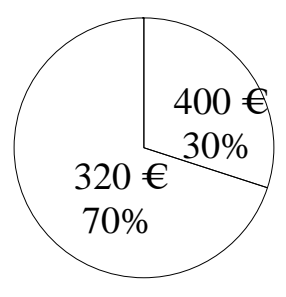

A
Lottery B

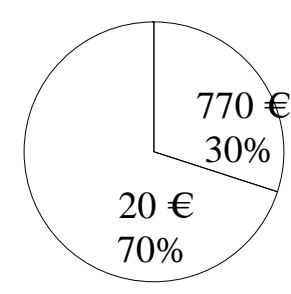

B 
Test 2. Q 14. Choose you preferred lottery

\section{Lottery A}

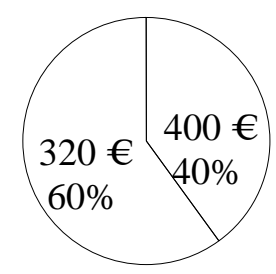

A
Lottery B

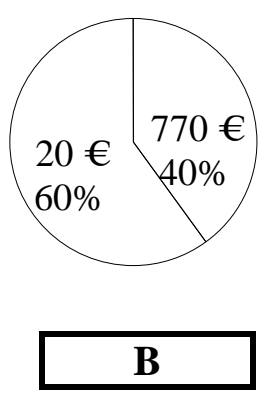

Test 2. Q 15. Choose you preferred lottery

\section{Lottery A}

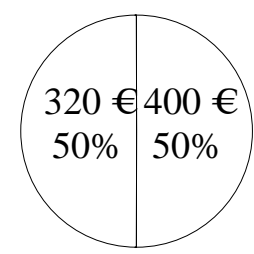

A
Lottery B

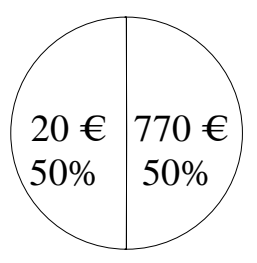

B

\section{Lottery B}

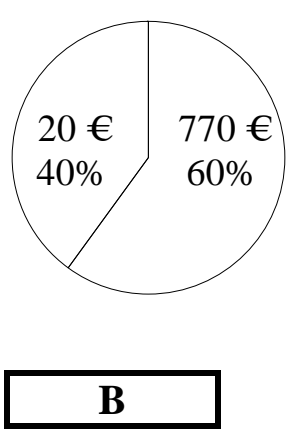


Test 2. Q 17. Choose you preferred lottery

Lottery A

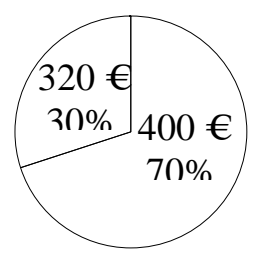

A
Lottery B

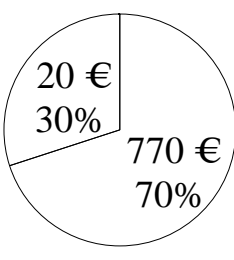

B

Test 2. Q 18. Choose you preferred lottery

\section{Lottery A}

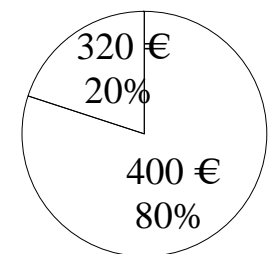

A

\section{Lottery B}

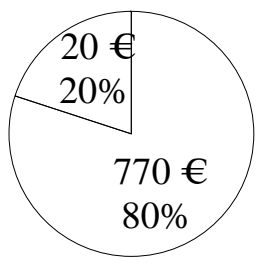

B

Test 2. Q 19. Choose you preferred lottery

\section{Lottery A}

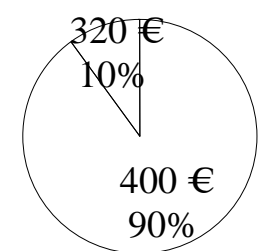

A
Lottery B

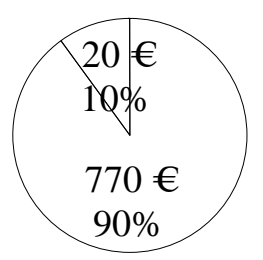

B 
Test 2. Q 20. Choose you preferred lottery

Lottery A

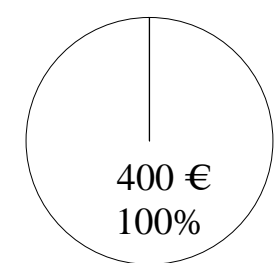

A
Lottery B

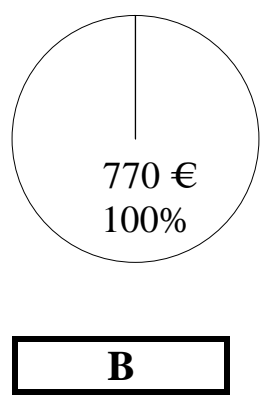




\section{TEST 3: PSYCHOMETRIC QUESTIONNAIRE}

This questionnaire will allow us to qualitatively assess your attitude for different types of risks (ethical, financial, health, social). Some questions may seem strange or surprising, but this questionnaire has global coherence. It is important to us that you answer all questions, while knowing that your answers will be treated anonymously and will remain completely confidential.

The test 3 includes 30 questions for which you must indicate your level of risk taking among 9 possible levels. For each statement asked, you must indicate the likelihood that you take part in the activity specified or you adopt the behaviour specified if you were in the situation described. You must then choose one of the 9 options ranging from "Not at all likely" to "Some (e)" by using the scale.

\begin{tabular}{|c|c|c|c|c|c|c|c|c|}
\hline 1 & 2 & 3 & 4 & 5 & 6 & 7 & 8 & 9 \\
\hline Not at all likely & $\begin{array}{c}\text { Not } \\
\text { likely }\end{array}$ & $\begin{array}{c}\text { Very few } \\
\text { likely }\end{array}$ & $\begin{array}{c}\text { Slightly } \\
\text { likely }\end{array}$ & $\begin{array}{c}\text { Moderately } \\
\text { likely }\end{array}$ & likely & $\begin{array}{c}\text { Very } \\
\text { likely }\end{array}$ & Extremely likely & Certain \\
\hline & & & & & & & & \\
\hline
\end{tabular}

\begin{tabular}{|c|c|}
\hline Question & $\begin{array}{l}\text { Your choice } \\
\text { (1 to 9) }\end{array}$ \\
\hline $\begin{array}{l}\text { 1. Admitting that your tastes are different from those of a friend. } \\
\text { 2. Going camping in the wilderness. } \\
\text { 3. Betting a day's income at the horse races. } \\
\text { 4. Investing } 10 \% \text { of your annual income in a moderate growth mutual fund. } \\
\text { 5. Drinking heavily at a social function. } \\
\text { 6. Taking some questionable deductions on your income tax return. } \\
\text { 7. Disagreeing with an authority figure on a major issue. } \\
\text { 8. Betting a day's income at a high-stake poker game. } \\
\text { 9. Having an affair with a married man/woman. } \\
\text { 10. Passing off somebody else's work as your own. } \\
\text { 11. Going down a ski run that is beyond your ability. } \\
\text { 12. Investing } 5 \% \text { of your annual income in a very speculative stock. } \\
\text { 13. Going whitewater rafting at high water in the spring. } \\
\text { 14. Betting a day's income on the outcome of a sporting event } \\
\text { 15. Engaging in unprotected sex. } \\
\text { 16. Revealing a friend's secret to someone else. } \\
\text { 17. Driving a car without wearing a seat belt. } \\
\text { 18. Investing } 10 \% \text { of your annual income in a new business venture. } \\
\text { 19. Taking a skydiving class. } \\
\text { 20. Riding a motorcycle without a helmet. } \\
\text { 21. Choosing a career that you truly enjoy over a more secure one. } \\
\text { 22. Speaking your mind about an unpopular issue in a meeting at work. } \\
\text { 23. Sunbathing without sunscreen. } \\
\text { 24. Bungee jumping off a tall bridge. } \\
\text { 25. Piloting a small plane. } \\
\text { 26. Walking home alone at night in an unsafe area of town. } \\
\text { 27. Moving to a city far away from your extended family. } \\
\text { 28. Starting a new career in your mid-thirties. } \\
\text { 29. Leaving your young children alone at home while running an errand. } \\
\text { 30. Not returning a wallet you found that contains } € 200 \text {. }\end{array}$ & \\
\hline $\begin{array}{l}\text { Note: In fact each question was followed by a table presenting the } 90 \\
\text { space we have modified the presentation and we put all question is on }\end{array}$ & \\
\hline
\end{tabular}




\section{TEST 4: SUBJECTIVE ASSESSMENT OF ATTITUDE TOWARDS RISKS}

Now, we ask you to evaluate your behaviour for different type of risks on a scale going from 1 (behaviour not at all risky) to 9 (behaviour more than extremely risky).

Test 4. Q1. In general, would you say that your behaviour and the decisions you take are:

\begin{tabular}{|c|c|c|c|c|c|c|c|c|}
\hline 1 & 2 & 3 & 4 & 5 & 6 & 7 & 8 & 9 \\
\hline Not at all risky & $\begin{array}{c}\text { Not } \\
\text { risky }\end{array}$ & $\begin{array}{c}\text { Very few } \\
\text { risky }\end{array}$ & $\begin{array}{c}\text { Slightly } \\
\text { risky }\end{array}$ & $\begin{array}{c}\text { Moderately } \\
\text { risky }\end{array}$ & Risky & $\begin{array}{c}\text { Very } \\
\text { risky }\end{array}$ & Extremely risky & $\begin{array}{c}\text { More than } \\
\text { extremely risky }\end{array}$ \\
\hline & & & & & & & & \\
\hline
\end{tabular}

Test 4. Q2. For your professional activity, would you say that your behaviour and the decisions you take are:

\begin{tabular}{|c|c|c|c|c|c|c|c|c|}
\hline 1 & 2 & 3 & 4 & 5 & 6 & 7 & 8 & 9 \\
\hline Not at all risky & $\begin{array}{c}\text { Not } \\
\text { risky }\end{array}$ & $\begin{array}{c}\text { Very few } \\
\text { risky }\end{array}$ & $\begin{array}{c}\text { Slightly } \\
\text { risky }\end{array}$ & $\begin{array}{c}\text { Moderately } \\
\text { risky }\end{array}$ & Risky & $\begin{array}{c}\text { Very } \\
\text { risky }\end{array}$ & Extremely risky & $\begin{array}{c}\text { More than } \\
\text { extremely risky }\end{array}$ \\
\hline & & & & & & & \\
\hline
\end{tabular}

Test 4. Q3. With regards to finance, would you say that your behaviour and the decisions you take are:

\begin{tabular}{|c|c|c|c|c|c|c|c|c|}
\hline 1 & 2 & 3 & 4 & 5 & 6 & 7 & 8 & 9 \\
\hline Not at all risky & $\begin{array}{c}\text { Not } \\
\text { risky }\end{array}$ & $\begin{array}{c}\text { Very few } \\
\text { risky }\end{array}$ & $\begin{array}{c}\text { Slightly } \\
\text { risky }\end{array}$ & $\begin{array}{c}\text { Moderately } \\
\text { risky }\end{array}$ & Risky & $\begin{array}{c}\text { Very } \\
\text { risky }\end{array}$ & Extremely risky & $\begin{array}{c}\text { More than } \\
\text { extremely risky }\end{array}$ \\
\hline & & & & & & & \\
\hline
\end{tabular}

Test 4. Q4. With regards to health, would you say that your behaviour and the decisions you take are:

\begin{tabular}{|c|c|c|c|c|c|c|c|c|}
\hline 1 & 2 & 3 & 4 & 5 & 6 & 7 & 8 & 9 \\
\hline Not at all risky & $\begin{array}{c}\text { Not } \\
\text { risky }\end{array}$ & $\begin{array}{c}\text { Very few } \\
\text { risky }\end{array}$ & $\begin{array}{c}\text { Slightly } \\
\text { risky }\end{array}$ & $\begin{array}{c}\text { Moderately } \\
\text { risky }\end{array}$ & Risky & $\begin{array}{c}\text { Very } \\
\text { risky }\end{array}$ & Extremely risky & $\begin{array}{c}\text { More than } \\
\text { extremely risky }\end{array}$ \\
\hline & & & & & & & & \\
\hline
\end{tabular}

